\title{
COMPETITIVOS EN LANAS, PERO NO EN PAÑOS: \\ LANA PARA LA EXPORTACION \\ Y LANA PARA LOS TELARES NACIONALES \\ EN LA ESPAÑA \\ DEL ANTIGUO REGIMEN
}

ANGEL GARCIA SANZ

Universidad de Valladolid

\section{RESUMEN}

La presencia en el mercado de tejidos importados (elaborados, precisamente, con lana castellana) fue compatible con una industria española pañera que se mantuvo vigorosa y que coexistió con la exportación de la lana en bruto hasta el siglo XIX. Este trabajo analiza el proceso de especialización parcial de la industria pañera española durante el Antiguo Régimen y muestra su adaptación a la ventaja comparativa que los tejedores castellanos tenian en el subsector de la lana de mediana y baja calidad.

\section{ABSTRACT}

A vigonous Spanish wool manufacturing industry during the Ancient Regime coexisted with an active export trade of raw wool from Castile. While foreign producers exhibited a clear comparative advantage on high quality fabrics, specialization in medium and low quality goods allowed Castilian wool textile producers to successfully compete against European imports (many of them made with Castilian wool) up to the XIXth century.

\section{INTRODUCCION *}

El objetivo de estas páginas es presentar unos primeros resultados sobre algunos temas relevantes que son recurrentes en la historiografía económica de

* Quiero manifestar mi agradecimiento, por las informaciones y comentarios que me han transmitido en relación con este texto, a Jean-Pierre Amalrich, Juan Helguera Quijada, José Ignacio Jiménez Blanco, Enrique Llopis, Leandro Prados, Jaume Torras y Gabriel Tortella, asi como a los evaluadores anónimos. 
la España del Antiguo Régimen y que aún están por clarificar, aunque sea a nivel de una primera aproximación o hipótesis fundada. En calidad de tal debe considerarse este escrito.

El argumento central de estas páginas se puede sintetizar en las cuatro siguientes afirmaciones. Primera, que entre los siglos bajomedievales y el final del Antiguo Régimen persistió en el pais una importante y muy difundida industria textil lanera, lo que cuestiona seriamente las valoraciones de la economía española durante aquella época, valoraciones que, enfatizando los aspectos agrarios y silenciando las realizaciones industriales y comerciales, califican genéricamente dicha economía de «colonial», «arcaica», «muy atrasada». Segunda, que la exportación de lana sin elaborar - uno de los argumentos más socorridos para sostener las referidas valoraciones injustificadamente peyorativasera racional económicamente, habida cuenta de las «ventajas relativas» que el medio natural y la historia institucional del pais otorgaban a la especialización productiva en torno a esta fibra, la cual se obtenía con una calidad y a unos costes que la hacían altamente competitiva en el mercado internacional. Tercera, que, por el contrario, los países importadores de lana española contaban con otro género de «ventajas relativas», que abarataban precisamente los costes de transformación de la lana extraída de España, de manera que sus géneros resultaban competitivos incluso en el mercado interior español, según se desprende del estudio comparado de costes de fabricación disponibles para finales del siglo XviII. Y cuarta, que, a pesar de que la exportación lanera -en realidad y por lo menos entre 1750 y 1800 sólo representó entre el 25 y el 30 por 100 de la lana producida - y de la importación de géneros extranjeros, la industria pañera tradicional del pais satisfizo el grueso de la demanda nacional y hasta la primera mitad del siglo XIX dio testimonio de su «fortaleza» aprovechando a fondo, y paradójicamente a primera vista, las posibilidades que aún le deparaba su viejo marco organizativo.

Es bastante probable que el atraso de la economía española respecto a la de otros paises europeos, claramente evidenciado durante la época contemporánea ${ }^{1}$, haya influido en la reconstrucción del pasado. En otras palabras, que

También deseo poner de manifiesto que este escrito se ha beneficiado del disfrute de una Acción Integrada Universidad de Valladolid-Universidad de Bolonia concedida por el Ministerio de Educación y Ciencia para el año 1992 (Acción 39 A), que fue renovada para el de 1993 (Acción 31 A), de la que fue responsable por parte italiana el Prof. Franco Cazzola. Tambien he contado para las últimas fases de elaboración con la ayuda económica de un proyecto de investiga. ción concedido por la Junta de Castilla y León para el estudio del proceso de industrialización en la Comunidad Castellano-leonesa.

1 Sobre esto puede verse Carreras Odriozola (1990) y Prados (1988). 
la necesidad de explicar el atraso contemporáneo seguramente ha forzado en sentido negativo la imagen del pasado real de la economía española. Pura teleologia mental.

\section{1. ¿UNA ECONOMIA «SEMICOLONIAL»O «COLONIAL»?}

No es infrecuente aún ver calificar a la economía castellana - de los territorios de la antigua Corona de Castilla, y, por extensión más o menos explícita, del conjunto de España- durante el Antiguo Régimen como una economía «muy atrasada», «semicolonial» o «colonial». Y uno de los argumentos favoritos que se esgrime para sustentar valoraciones tan negativas es que el principal renglón de las exportaciones consistía en lana sin elaborar.

Es incuestionable que la industria tradicional española no aprovechaba todas las ventajas relativas y posibilidades en general que, en principio, le otorgaba la producción in situ de una abundante y cualificada materia prima. $Y$ no es susceptible de discusión que otros países europeos - Inglaterra, los Países Bajos, Italia o Francia, según la etapa histórica - fabricaban paños con la lana española que importaban, paños cuyo destino comercial era frecuentemente la misma España.

Pero el que la lana fuera durante siglos el principal capítulo de la exportación era perfectamente compatible con la existencia en nuestro país de una respetable industria pañera.

Lo que se va conociendo, a la vista de las contribuciones historiográficas de las últimas décadas, sobre la difusión e importancia de la industria pañera es congruente con la reivindicación formulada de una valoración menos peyorativa, y con los datos y estimaciones sobre exportación-transformación de la lana que más adelante expondré.

Sin pretender en absoluto ser exhaustivo y con referencia a la industria pañera de las diversas calidades, hay que empezar mencionando el cuadro verdaderamente estimulante de la pañería castellana entre los siglos XIV y XV tan bien pintado por Paulino Iradiel -en especial, para la Submeseta Sur, con Cuenca a la cabeza- 2 . Otro tanto cabe afirmar de la pañería cordobesa entre la Baja Edad Media y finales del xvi, según los trabajos de Córdoba de la Llave y Fortea ${ }^{3}$. Por su parte, Hilario Casado ha desvelado la profusión de centros pañeros en la España de mediados del siglo Xvi al estudiar la distribución

2 Iradiel (1974).

3 Córdoba de la Llave (1990), Fortea (1980). 
del pastel importado por los mercaderes burgaleses ${ }^{4}$. Para el siglo XviI los testimonios conocidos de especialización industrial pañera son más numerosos: aparte de las Reales Fábricas dedicadas a la pañería 5 , tenemos los casos ilustrativos de Amusco, Astudillo y Palencia ${ }^{6}$, el de Béjar ${ }^{7}$, el de Avila ${ }^{8}$, el de Pradoluengo con larga tradición anterior ${ }^{9}$, los de Hervás y Torrejoncillo en Extremadura ${ }^{10}$, el de Alcoy ${ }^{11}$, los numerosos de Cataluña -Esparraguera, Olesa, Sabadell, Terrassa y otros-- ${ }^{12}$, el de Antequera en Andalucía ${ }^{13}$, los de Santa Maria de Nieva, Bernardos y Riaza en la provincia de Segovia ${ }^{14}$. Por su parte, el caso de la ciudad de Segovia ${ }^{15}$ es representativo de la trayectoria seguida por la pañería de calidad desde, al menos, principios del xVI y hasta el primer tercio del XIX, con la particularidad de que, según ha mostrado Felipe Ruiz Martín ${ }^{16}$, en las últimas décadas del Quinientos la producción pañera segoviana poco tenía que envidiar, por su cantidad y por su primor, a la de los más importantes centros textiles de la Europa de entonces.

Aunque en esta sumaria panorámica sólo se mencionan los núcleos textiles estudiados y mejor conocidos — ¡cuántos quedan aún por estudiar! ¿No es sorprendente, por lo inesperado, lo descubierto por Carmona Badía respecto a la lenceria en Galicia? ${ }^{17}$, su mera existencia evidencia lo abusivo del calificativo de «colonial» adjudicado a la economía castellana $-\mathrm{y}$ por extensión española - para los siglos bajomedievales y modernos.

Quien haya leido las Memorias de Larruga sabe muy bien que por doquier se transformaban materias primas - no sólo lana: lino, esparto, seda, mineral de hierro, pieles, etc. $-y$, hay que subrayarlo, Larruga fue más generoso en noticias para la situación industrial de su tiempo - fines del xvIII- que respecto al estado de las manufacturas durante la segunda mitad del siglo xvi, etapa culminante de las actividades industriales en el interior peninsular.

4 Casado Alonso (1990).

s Sobre la de Guadalajara, González Enciso (1980).

- Garcia Colmenares (1992).

7 Ros Masana (1993).

${ }^{8}$ Martín Garcia (1989); respecto a la industria lanera, pp. 67-204.

9 Ojeda San Miguel (1984).

10 Garcia Pérez (1992) y LLopis (1993).

11 Aracil y García Bonafé (1974).

12 Torras Elias (1984), Muret Pons (1989), Benaul (1991).

13 Parejo Barranco (1987).

14 García Sanz (1986), pp. 248-256.

15 La historia de la pañería segoviana empieza a contar con una copiosa bibliografía: Larruga (1791, tomos X, XI y XII), Lecea García (1897), Marqués de Lozoya (1921), Ruiz Martin (1965. 1967), Le Flem (1976), Garcia Sanz (1986, 1987, 1989, 1991a, 1991b y 1991c).

16 Ruiz Martin (1965-1967).

17 Carmona (1990). 


\section{GANADERIA LANAR, PRODUCCION Y EXPORTACION DE LANA EN LA SEGUNDA MITAD DEL SIGLO XVIII}

Porque ¿qué representaba la lana exportada respecto a la lana producida? Esta es la verdadera cuestión, nunca aclarada, aunque sea como estimación razonable ${ }^{18}$. A este respecto me atrevo a afirmar, como estimación razonable abierta a mejor información documental, que a mediados del siglo xvirl sölo se exportaba la cuarta parte de la lana útil para la pañería que se esquilaba en el país y que, al final de la centuria, la exportación apenas alcanzaba a significar el 30 por 100 de la lana producida.

\section{CUADRO 1}

Ganadería lanar española (c. 1750 y 1865)

\begin{tabular}{|c|c|c|c|c|}
\hline Territorios & $\begin{array}{l}\text { c. } 1750 \\
\text { cabezas }\end{array}$ & $\%$ & $\begin{array}{c}1865 \\
\text { cabezas }\end{array}$ & $\%$ \\
\hline \multicolumn{5}{|l|}{ a) Territorios castellanos: } \\
\hline Galicia ....................... & 2.011 .422 & 8,3 & 1.538 .304 & 6,8 \\
\hline $\begin{array}{l}\text { Castilla la Vieja y León, con } \\
\text { Asturias, Cantabria y Rioja ....... }\end{array}$ & 8.864 .308 & 36,4 & 7.846 .562 & 34,9 \\
\hline $\begin{array}{l}\text { Castilla-La Mancha, con Madrid } \\
\text { y Murcia } \ldots \ldots \ldots \ldots \ldots \ldots \ldots \ldots\end{array}$ & 3.9601 .93 & 16,3 & 3.164 .184 & 14,1 \\
\hline Extremadura...$\ldots \ldots \ldots \ldots \ldots$ & 1.340 .772 & 5,5 & 2.452 .762 & 10,9 \\
\hline Andalucía $\ldots \ldots \ldots \ldots \ldots \ldots \ldots$ & 2.510 .055 & 10,2 & 2.242 .578 & 10,0 \\
\hline Total ............. & 18.687 .050 & 76,7 & 17.242 .390 & 76,7 \\
\hline b) Resto del pais ${ }^{1}$ & 5.664 .070 & 23,3 & 5.226 .579 & 23,3 \\
\hline Total de España .................. & 24.351 .120 & 100,0 & 22.468 .969 & 100,0 \\
\hline
\end{tabular}

1 Las cifras de 1750 son resultado de una extrapolación a partir de los datos del Censo de 1865. Comprende, aparte de los territorios históricos de la Corona de Aragón, al Pais Vasco, Navarra y Canarias.

FUENTES: Los datos de alrededor de 1750 son los del Catastro de la Ensenada publicados por el GRUPO '75 en La economía del Antiguo Régimen. La "renta nacional» de la Corona de Castilla, Universidad Autónoma, Madrid, 1977, p. 109. Los de 1865 proceden del Censo de la ganadería de España según el recuento verificado en 24 de septiembre de 1865, Madrid, 1868.

18 Las principales aportaciones historiográficas sobre la exportación de lana española se deben a Basas Fernandez (1963), Lapeyre (1974 y 1981), Israel (1980), Rahn Phillips (1982 y 1983), Bilbao y Fernández de Pinedo (1982), Bilbao (1983). 
La primera de estas estimaciones, para los años centrales del siglo, se fun$\mathrm{da}$ en los datos que se presentan en el Cuadro 1 sobre el contingente ganadero lanar de toda España para mediados del siglo xvill y para $1865^{19}$. El número de cabezas para los territorios no contemplados por el Catastro de la Ensenada hacia 1750 ha sido estimado a partir de la extrapolación de la importancia ganadera que dichos territorios tenían en el Censo de la Ganadería de España de 1865 , muy digno de crédito a juicio de quienes lo han analizado ${ }^{20}$. La coherencia en los porcentajes de distribución del ganado en los territorios castellanos entre una y otra fecha contituyen una garantía de la fiabilidad de la extrapolación realizada: sólo Extremadura discrepa, caso excepcional por razones bien conocidas.

Para calcular cuál podía ser la producción de lana utilizable en la pañería de la cabaña ovina hacia 1750 , he partido del supuesto - sigo en esto las razonables estimaciones de Parejo Barranco, aun a sabiendas de que el marco cronológico de estas páginas es otro ${ }^{21}$ - de que el 20 por 100 de los lanares, casi todos los de raza "churra», no producía lana utilizable para la fabricación de paños - se empleaba en colchones, sombreros, alfombras, tapices, etc.-. Así que los 24,3 millones de lanares quedaban reducidos a 19,5 millones de cabezas productoras de lana susceptible de ser convertida en paño. Es una estimación aceptable que el rendimiento en lana por cabeza de las diferentes razas ovinas era de 2 kilogramos 22 . En conclusión, los 19,5 millones de cabezas indicadas producian unos 3,388 millones de arrobas de lana en sucio, equivalentes a 38.962 Tms.

Consideremos ahora cuánta lana se exportaba por aquella época. Entre 1750 y 1759 se extrajeron, como media anual, 332.344 arrobas en limpio y 31.657 en sucio ${ }^{23}$. Reducidas las primeras a su peso en sucio - la lana al ser lavada perdía aproximadamente el 60 por 100 de su peso ${ }^{24}$, tenemos 830.860 arrobas, que sumadas a las que salian en sucio, hacen 862.517 , esto es, $9.918 \mathrm{Tms}$. Esta cantidad representa el 25,44 por 100 de la lana producida útil

${ }^{19}$ Deseo agradecer a Juan Ortega, delegado en Valladolid del Instituto Nacional de Estadística, las facilidades que me ha prodigado para obtener las cifras del Censo ganadero de 1865.

${ }^{20}$ Grupo de Estudios de Historia Rural (1991), pp. 79-93.

21 Parejo Barranco (1989), pp. 115-146.

22 Tengo bien documentado, para los rebaños trashumantes esquilados en Segovia, que los rendimientos medios por cabeza eran, entre el siglo XVIII y el XIX, de 2,3 kgs. -esto es, 5 libras por vellón o, si se prefiere, cada 5 cabezas producian una arroba de lana en sucio (11,5 kgs.).

${ }^{23}$ Arcbivo General de Simancas, sec. Dirección General de Rentas, 1. ${ }^{a}$ Remesa, leg. 2.598.

${ }^{24}$ Aunque esta es la estimación más rigurosa, no hay que extrañarse de que los coetáneos sostuvieran, por la facilidad implicita en el cálculo, que la reducción de peso de la lana sucia era del 50 por ciento. 
para la industria pañera. El resto $-2,525$ millones de arrobas, equivalentes a 29.048 Tms. - sería el consumo aparente de la industria pañera nacional.

Se podria pensar que, aunque tan sólo se exportara esa proporción de lana, la extraida era precisamente la más fina, la fina merina. Para empezar, esto no es cierto, como demostraré en el siguiente apartado, pero, aun dando por buena esta opinión errónea, debe tenerse en cuenta que hacia mediados del XVIII habia en el pais alrededor de 6 millones de cabezas de ganado fino ${ }^{25}$, de ellos, unos 3,5 millones estaban integrados en la Mesta ${ }^{26}$, los demás eran estantes y trasterminantes, o pertenecian a los territorios de la Corona de Aragón, donde no hay que olvidar que también era notable la trashumancia entre el valle del Ebro y los zonas montañosas que lo ciñen ${ }^{27}$. Estos 6 millones de ganado fino, con unos rendimientos algo superiores a la media $-2,3 \mathrm{Kgs}$. por vellón-, producian como 1,2 millones de arrobas de lana fina en sucio, esto es, 13.800 Tms. Descontadas de éstas las 9.918 Tms. que se exportaban, aún quedaban en el pais $3.882 \mathrm{Tms}$., esto es, 337.565 arrobas, bastante más de lo que cualquier país importador recibía por entonces.

Por lo que respecta a la estimación para finales del siglo - que la exportación lanera apenas alcanzaba al 30 por 100 de la producción-, parto del supuesto razonable de que hacia 1800 habia unas 800.000 cabezas menos que por 1750 , habida cuenta de que entre 1750 y 1865 disminuyó la cabaña lanar en 1,882 millones de cabezas y considerando que el ritmo del decrecimiento fuera uniforme entre ambas fechas ${ }^{28}$. Asi hacia 1800 tendríamos 23,551 millo-

25 Esta afirmación se fundamenta en los resultados de los recuentos de ganado fino que se hicieron entre 1770 y 1788 , datos que se encuentran en el expediente 34 del legajo 363 de la Sección del Consejo Supremo de Hacienda (Junta de Comercio y Moneda) del Archivo General de Simancas. Ha sido Ricardo Franch Benavent (1991) quien ha descubierto y analizado este importantísimo expediente, el cual constituye también en estas páginas una fuente de información fundamental. Agradezco al autor el que me enviara una separata de su artículo, verdaderamente memorable.

26 Hay que subrayar el considerable avance de la investigación sobre el tema mesteño experimentado en las últimas décadas, a partir del clásico libro de Klein (1981, 1. ed. 1920). Bishko (1982) presentó un espléndido estado de la cuestión al respecto. Seguramente es el conocimiento de la gestión económica de las grandes explotaciones trashumantes el campo en el que los progresos han sido mayores: Llopis (1980 y 1982).

27 Sorprende la escasa investigación realizada respecto a la trashumancia aragonesa si se compara con la amplia historiografía mesteña. Es esperanzadora la aparición de un reciente libro al respecto: Fernández Otal (1993).

28 Los datos sobre la cabaña lanar ofrecidos por el Censo de Frutos y Manufacturas de 1799 (Madrid, 1803) no ofrecen garantia alguna. Dicho documento quizá contenga algunas cifras correctas para esta o aquella provincia, pero no hay duda de que sus datos agregados no pueden ser admitidos por las numerosas deficiencias explícitas que contiene: por ejemplo, en Galicia, Córdoba y Guipúzcoa sólo se cuentan corderos; en Canarias sólo carneros y otro tanto parece ocurre en Soria. Además, ofrece rendimientos en lana por cabeza verdaderamente disparatados: por 
nes de lanares, de las que serían productoras de lana utilizable para la industria pañera 18,841 millones, las cuales producirian 3,276 millones de arrobas de lana en sucio. Por lo demás, consta documentalmente ${ }^{29}$ que la cantidad media anual de la lana exportada en la década de 1787-1796 fue de 0,966 millones de arrobas - reducido todo lo exportado a lana en sucio o sin lavar-, que representan un 29,49 por 100 de la lana producida, por lo que el consumo aparente de la industria nacional sería de 2,310 millones de arrobas -el 70,51 por 100 de la producción-. Esta estimación final coincide casi exactamente con la que ofrece Canga Argüelles ${ }^{30}$, que afirma que, «según razones que los intendentes dieron», antes de 1806 las «fábricas» nacionales consumian 919.032 arrobas de lana lavada, que equivalen a 2,297 arrobas en sucio. Este dato es, en mi opinión, garantía de la corrección de las estimaciones realizadas, que se exponen sintéticamente en el Cuadro 2.

La falta de lana, que a veces se denuncia, no era una situación de carácter general en el tiempo y en el espacio, sino más bien excepcional. Respondía a particulares circunstancias, episódicas. En la historia de la pañería segoviana he detectado algunas de esas situaciones de carestia de lana. Y era precisamente en esas circunstancias cuando los fabricantes recurrían al derecho de tanteo sobre las lanas compradas para exportar. Este derecho afectó hasta la tercera parte de dichas lanas desde 1462 a 1551 ; desde esta fecha a 1779 se aplicó a la mitad de las mencionadas lanas; desde 1779 se refirió a «las lanas conducentes a su fábrica», esto es, a cuanta lana precisaran los fabricantes.

En conclusión, no hay contradicción alguna en que, por una parte, la lana exportada fuera el principal renglón de la exportación ${ }^{31}$ y en que, a la vez, la

ejemplo, resulta que en León se precisan 17,39 cabezas para obtener una arroba de lana, mientras que en Avila los ganaderos lograban una arroba con 0,37 cabezas. ;Afortunados abulenses y desdichados leoneses! Esto no hace más que confirmar las opiniones, formuladas hace ya tiempo por Fontana (1967), sobre la validez general de las cifras proporcionadas por este Censo: la fecha "estratégica” a que se refiere el Censo - y, por lo tanto, sus potenciales posibilidades como dato de arranque para estudiar las transformaciones económicas en la España contemporánea- no puede hacernos indulgentes con disparates y errores explícitos que inutilizan los datos agregados. ¿Cómo dar por bueno que el Catastro del Marqués de la Ensenada cuente 18,687 millones de lanares en los territorios de la Corona de Castilla y el Censo ganadero de 1865 contabilice en los mismos territorios 16,877 millones, mientras que el Censo de Frutos y Manufacturas de 1799 sólo sume 8,204 millones? ¿Hay alguien que tenga noticia de semejante hecatombe ganadera y de tan brillante recuperación ente 1799 y 1865 ?

${ }^{29}$ Archivo General de Simancas, sec. Consejo Supremo de Hacienda (Junta de Comercio y Mo. neda), leg. 363, exp. 34 .

30 Canga Argüelles (1834), p. 39.

31 Fontana (1970), p. 12., indica que el valor de la lana exportada en 1792 alcanzó los 130,6 millones de reales, lo que suponia el 33 por ciento del valor de todas las exportaciones españolas hacia los demás paises europeos. 
industria pañera estuviera muy difundida y contara con centros especializados no sólo en géneros ordinarios, sino también en paños selectos.

\section{CUADRO 2}

Producción, exportación y consumo aparente de lana

\begin{tabular}{|c|c|c|c|c|}
\hline Conceptos & c. 1750 & & c. 1800 & \\
\hline \multirow{3}{*}{$\begin{array}{l}\text { Total número de cabezas lanares, en millones } \ldots \ldots \ldots . . \\
\text { Cabezas productoras de lana utilizable por la industria } \\
\text { pañera, en millones } \ldots \ldots \ldots \ldots \ldots \ldots \ldots \ldots \ldots \ldots \ldots\end{array}$} & 24,351 & & 23,551 & \\
\hline & 19,481 & & 18,841 & \\
\hline & & $\%$ & & $\%$ \\
\hline Producción de lana en sucio, en millones de arrobas $^{1}$ & 3,388 & 100,00 & 3,276 & 100,00 \\
\hline Lana exportada, en millones de arrobas ${ }^{2} \ldots \ldots \ldots \ldots \ldots$ & 0,862 & 25,44 & 0,966 & 29,49 \\
\hline 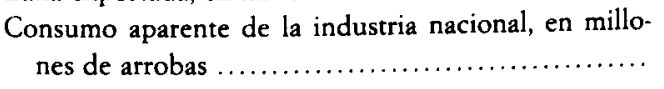 & 2,526 & 74,56 & 2,31 & 70,51 \\
\hline
\end{tabular}

1 Cada cabeza produce 2 kilogramos de lana en sucio.

2 Para c. 1750 es la media anual de lo exportado durante el decenio 1750-1759. Para c. 1800 es la media anual de lo exportado en la década 1787-1796.

FuENTEs: Para el número de cabezas, estimaciones a partir de los datos de las fuentes indicadas en el Cuadro 1.

Para la exportación de lana: los datos de 1750-1759, en la sec. Dirección General de Rentas, 1." Remesa, leg. 2.598, del Arcbivo General de Simancas, los datos de 1787-1796, en sección Consejo Supremo de Hacienda (Junta de Comercio y Moneda), leg. 363, exp. 34, del mismo Archivo.

Una consideración final en este apartado: la valoración del impacto de la reforma agraria liberal sobre la ganadería lanar. Por los datos que ofrezco hay que concluir que la incidencia en sentido negativo fue escasa. En los 115 años que van de 1750 a 1865 la cabaña ovina apenas había descendido en 2 millones de cabezas. Otra cosa es que los lanares trashumantes hubieran pasado de los 4 ó 5 millones a tan sólo 1,873 millones en 1865: la mayor parte de ellos se habian hecho estantes, integrándose así con la labranza que, si bien avanzó sobre tierras antes incultas, producía también más cereales pienso y procuraba mayores superficies de rastrojeras, barbecho y eriazo, que continuaron, como es sabido, sujetas a «la derrota de las mieses», servidumbre que la reforma agraria liberal no logró abolir, aunque lo intentó ${ }^{32}$.

32 Sobre esto puede verse Garcia Sanz (1985b). 


\section{SE EXPORTABAN LANAS BASTAS, ORDINARIAS, BURDAS, ENTREFINAS, FINAS, ETC.}

Veamos ahora la trascendental cuestión de la calidad de la lana exportada. Como he adelantado, no se puede sostener que la extraida fuera exclusivamente lana de calidad, esto es, fina merina. Esta afirmación desmiente un supuesto que tradicionalmente han dado por bueno los estudiosos del tema, algunos de los cuales incluso han formulado toda una interpretación de la trayectoria de las exportaciones laneras españolas en función de los mayores o menores requerimientos de lana merina por parte de las industrias extranjeras.

Varios, y de peso, creo yo, son los testimonios documentales que demuestran que, junto a una cantidad indeterminada de lana fina merina, se extraia una cantidad también indeterminada de lanas bastas, ordinarias y entrefinas. La proporción de aquélla y de éstas en el conjunto de la lana exportada debió ser variable, según los cambios cualitativos de la demanda exterior, aunque es razonable suponer que en general la proporción correspondiente a la lana fina fue mayoritaria. Esta situación arranca, que nos conste documentalmente, por lo menos del primer tercio del siglo xvir y se mantiene hasta las primeras décadas del siglo XIX.

El, por ahora, principal testimonio que se puede invocar en apoyo de lo que afirmo es la misma legislación. Así, la Real Cédula de 24 de diciembre de 1625 sobre el derecho de tanteo de lanas a favor de los fabricantes establece que:

... el tanteo contenido en las dichas leyes, sea no sólo de la mitad de las lanas finas, ó bastas, ó añinos que se compraren para sacar de estos reynos, sino también de las que se compraren para revender en ellos, ó en otra cualquier manera, como no sea para fabricarlas, y con que, en quanto á las lanas bastas que se compraren para sacarlas del reyno, se pueda extender, y se extienda la dicha facultad del tantear á las dos tercias partes, el cual tanteo se concede solo en fa. vor de los hacedores de paños, rajas, ó bayetas, ú de otra qualquier especie de labor de lana, y con las demás calidades contenidas en las dichas leyes ${ }^{33}$.

Pero ya bastante antes de 1625 debía ser práctica común el exportar cualquier clase de lana: William D. Phillips y Carla Rahn Phillips han analizado con detenimiento un envio de lanas a Brujas en los años setenta del xvi y en la lista de precios de la lana extraída que publican - precios declarados por los mismos exportadores en pleito con los aseguradores- se aprecia una

${ }^{33} \mathrm{El}$ texto de esta importante Cédula fue publicado por Larruga (1791), vol. XI, pp. 266-275; el texto aqui reproducido está en la p. 268. 
gran diversidad, hecho que sólo se puede atribuir a las muy diversas clases y calidades de la lana ${ }^{34}$.

Por la Ley 6 del Título 16 del Libro 9.' de la Novísima Recopilación, fechada en 23 de junio de 1699, se ordena que

Habiéndose reconocido los graves perjuicios que se siguen á las fäbricas de texidos de estos reynos y á la causa pública de las extracciones, que de algún tiempo á esta parte se hacen para Reynos extraños de lanas bastas y ordinarias, de que se surten dichas fábricas, hemos resuelto prohibir estas extracciones general y absolutamente...

En su Theorica y Practica de Comercio y Marina, cuya primera edición aparece en 1724 , Gerónimo de Uztáriz escribe respecto a lo que aquí nos interesa:

Aunque la saca de Lanas ordinarias està vedada por la citada Cedula del año 1699, no estoy bien informado de si todavia subsiste [la exportación, se entiende], y dudo si su permanencia es conveniente, ò no por aora, respecto de que en algunas Provincias ay cantidad grande de ellas, y es muy natural que no las podràn consumir todas hasta que se establezca mayor numero de Telares; $y$ assi suspendere mi dictamen en este punto, hasta lograr noticias mas puntuales de lo que ay en esto; pero en caso de permitirse su extraccion, convendrà practicar lo mismo que he propuesto para las Lanas finas ${ }^{35}$.

Disposiciones sobre el tanteo fechadas en 1751, 1752, 1767 y 1770 reiteran la prohibición de exportar lanas «bastas y comunes», lo que prueba que no se observaba lo mandado en 1699: Ley 7 del Título 6 del Libro 9. ${ }^{\circ}$ de las Novísima Recopilación. En 1770, en concreto, la Junta general de Comercio exigia el cumplimiento de la ley de 1699 en los siguientes términos:

para contener el abuso de extraer lanas ordinarias extendido á las negras y pardas, conocidamente comprehendidas en las clases de aquellas, y estimadas siem. pre como el material más propio y necesario para las fábricas de paños bastos, de que se viste el común de la Nación... ${ }^{36}$

A partir de 1751 la legislación sobre el tanteo de lanas declara tanteables por los fabricantes no sólo las finas, sino también las lanas entrefinas compradas para exportar. Pero ¿de qué calidad eran las lanas entrefinas? Oigamos lo que al respecto piensa, en informe fechado hacia 1782, la Sociedad Económica de

34 Phillips y Rahn Phillips (1977).

35 Uztáriz (1742), pp. 283-284.

36 Nota 3 de la Ley 6 del Título 16 del Libro 6. de la Novísima Recopilación. 
Soria, que achaca la decadencia de la industria lanera en su provincia, entre otras causas, a

La extracción de Lanas churras y riberiegas, de que se surtian y surten las Fábricas, que en otros Paises se llaman estantes, y en las Leyes y Autos Acordados se distinguen con los nombres de bastas, burdas y ordinarias, disfrazándose esta extracción prohibida con el dictado de entrefinas, desconocido en las Leyes del Reyno ${ }^{37}$.

Al ilustrado intendente de Segovia y director de su Sociedad Económica, José Antonio de Horcasitas, esta era la opinión que le merecian las lanas entrefinas.

... deseara [yo] que se olvidase el uso de este nombre inventado por los tratantes, para sacar con este Título las (lanas) ordinarias, como advierte el Ilustrísimo Autor de la Educación Popular [esto es, Campomanes] ${ }^{38}$.

Todavía en 1783 y en 1789 se hubo de reiterar la prohibición de exportar lanas «burdas y ordinarias» ${ }^{39}$. Es más, hay que sospechar que una de las épocas en que mayor cantidad de lana ordinaria se extrajo fraudulentamente - una forma fácil de hacerlo era envolverla con lana fina en el interior de las sacas- fue precisamente durante las décadas postreras del siglo Xvil y en los dos primeros decenios del xIX: la gran estimación y fuerte demanda de lanas finas castellanas incitaron a los extractores a perpetrar tan lucrativo engaño - todo se vendía al precio de lo fino- consistente en mezclar las lanas «churras con las merinas». A partir de aproximadamente 1820 , cuando se hunden las exportaciones laneras españolas por la competencia de las lanas sajonas, son numerosos los coetáneos que consideran que uno de los motivos de la pérdida de estimación de nuestras lanas es el comportamiento irresponsable y fraudulento de los extractores durante los buenos tiempos pasados 40 .

No es difícil imaginar las razones por las que los cobradores de la «renta de la lana» en las aduanas - tanto cuando estuvo arrendada como cuando se

37 Este texto está tomado del informe de la Sociedad Económica de Soria sobre las causas de la decadencia de las Fábricas de lana en su Provincia, que se publicó en las ACTAS Y MEMORIAS DE LA REAL SOCIEDAD ECONOMICA DE LOS AMIGOS DEL PAIS DE LA PROVINCIA DE SEGOVIA, Segovia, 1785, vol. I, p. 170. Lo subrayado está así en el texto.

38 Texto tomado del «Extracto de Informe dado a la Real Junta de Comercio sobre qué lanas conviene o no permitir su extracción», redactado por Josef Antonio de Horcasitas, intendente de Segovia, y publicado en ACTAS Y MEMORIAS..,, op. cit., Segovia, 1786, vol. II, pp. 316-326.

${ }^{39}$ Respectivamente para sendas fechas: Leyes 8 y 9 del Titulo 16 del Libro 9.0 de las Novisima Recopilación.

40 Sobre esto puede verse García Sanz (1978 y 1985a). 
administró directamente por funcionarios de la Hacienda regia- eran cómplices del fraude de los exportadores: según precisa Lapeyre ${ }^{41}$, el derecho más antiguo en el tiempo, al que desde 1558 se irán superponiendo otros, gravaba la lana en atención a su calidad. Interesaba pues a los arrendatarios de la renta y, en definitiva, a las arcas reales considerar que toda la lana exportada era de la mejor calidad. Por su parte, los extractores ¿se iban a denunciar a sí mismos como infractores de la prohibición de exportar lanas bastas, bien explícita al menos desde 1699? Por lo demás, soportaban pagar más de lo debido en aduana por el lucro extraordinario que esperaban obtener mediante la venta, en el exterior, de la lana ordinaria a los precios de la lana fina con la que iba mezclada.

En conclusión, a la vista de estos datos y evidencias se impone revisar, por lo menos, las explicaciones - si no los datos de base- ofrecidas sobre la trayectoria de la exportación lanera.

\section{COMPETITIVOS EN LANAS, PERO NO EN PAÑOS: LOS HECHOS}

En este apartado se trata de presentar varios testimonios de época, fechados en torno a 1800 , que evidencian -y permiten también apuntar explicaciones- que los paños extranjeros confeccionados con lana previamente importada de España podian ser competitivos, y de hecho lo eran, en el mercado interior español.

El primer testimonio lo proporciona la Sociedad Económica de Segovia. Se trata de un informe que hizo la institución en 1791 para responder al interrogatorio mandado por Bernardo Iriarte, «Ministro de la Junta de Comercio y Moneda», que se refería a las siguientes cuestiones, justamente las que aquí nos interesan:

Es constante que en España abunda la lana; también lo es que los Extrangeros la extraen, introduciéndonosla manufacturada, y que considerados los gastos de ida y vuelta tienen á lo menos sus géneros un recargo de 100 por 100 que no tienen nuestros géneros nacionales. Ahora pues ¿cómo pueden aquellos industriosos Fabricantes vendernos sus texidos á precios equivalentes á los nuestros? ¿Será porque trabajen mas horas sus operarios? ¿Será porque posean mayor destreza? ¿Porque usen de métodos y máquinas que faciliten, aceleren y perfeccionen las varias operaciones? ¿Porque mezclen con nuestras lanas finas otras lanas mas ordinarias y menos costosas? ¿Porque fabriquen con menos ley? ¿O será á

${ }^{41}$ Lapeyre (1981), pp. 171-177. 
caso el conjunto de todas estas circunstancias y de otras que ignoro, y no acierto á discurrir? ${ }^{42}$.

La Sociedad segoviana se tomó muy en serio la respuesta a estas cuestiones: mandó examinar paños de Sedán, de la fábrica de San Fernando de Henares y de la segoviana de Laureano Ortiz de Paz, así como paños confeccionados por diversos fabricantes de la ciudad, de los que además logró informes detallados. Los resultados, en lo que aquí interesa, se sintetizan y presentan en el Cuadro 3.

La primera conclusión es que el encarecimiento de los paños extranjeros por la repercusión, primero, de los costes de exportación de la lana y, después, de importación de los géneros era considerablemente menor que el admitido generalmente en España - 100 por 100 y aún más-. En realidad, según los cálculos de la Segoviana reflejados en el Cuadro, ese incremento de costes era tan sólo de un 22,01 por 100 (suma de A3, A4, A5, A7, B2 y B3).

La mayor parte de ese recargo del 22,01 por 100 no puede ser imputada al coste del transporte, sino al pago de los derechos aduaneros al extraer la lana -repercutía en un 5,47 en los costes totales de los paños, pero respecto al precio de la arroba de lana lavada los referidos derechos significaban un 30,70 por $100(66,31$ reales respecto a 216, que era el precio de la arroba en limpio) - y al importar los paños —un 11,26 por 100 del coste total-. En definitiva, del 22,01 por 100 de los recargos, 16,73 se debia al fisco español y tan sólo 4,74 al transporte - no se considera, claro, el coste, pequeño relativamente por lo demás, del porte de los paños extranjeros desde los puertos hasta Madrid, porque en ese gasto también incurrian los paños nacionales-. Estas consideraciones ponen en evidencia la importancia de los recargos aduaneros, pero a la vez dejan claro que eran insuficientes para impedir la competencia victoriosa de los paños extranjeros hechos con lanas españolas. Si de verdad se hubiera deseado anular con medidas arancelarias los beneficios que obtenían los fabricantes extranjeros, jse habrian tenido que incrementar los derechos aduaneros en un 107,34 por 100! En efecto, la cantidad de los derechos pagados - 341.215 reales- debería aumentar en 366.171 reales más, que eran los beneficios que obtenian los fabricantes extranjeros - un 17,96 por 100 de la inversión total realizada-. En suma, 707.387 reales, lo que hubiera supuesto un recargo aduanero que habría significado algo más de la tercera parte de los costes totales de los paños.

42 ACTAS Y MEMORIAS..., op. cil., vol. IV, Segovia, 1793, pp. 31-32. También hay referencias a este interrogatorio de Iriarte en el vol. II, Segovia, 1786, p. 12. 


\section{CUADRO 3 \\ Costes de exportación de lana española y de importación de paños extranjeros con ella fabricados en 1791}

Reales

$\%$

a) Desde la compra de la lana hasta la fábrica extranjera:

1. Valor de 3.306 arrobas * de lana en sucio, a 103 reales arroba ....

2. Coste de lavado, ensacado de las 1.683 arrobas a que queda reducida la lana, a 7 reales arroba

340.518

16,70

. Comisión del intermediario $(3 \%)$

23.142

1,13

10.910

0,53

4. Transporte desde Segovia, por Burgos hasta su embarque en Bilbao, a 9 reales por arroba

5. Derechos de exportación (antiguos y nuevos ), a 66,31 reales arroba

111.622

5,47

$15.040 \quad 0,74$

20.655 adelantada por comprador extranjer

537.040

26,34

TOTAL

b) Fabricación de los paños y su importación hasta Madrid:

1. Coste de fabricación de 841 paños 32 nos. color grana, de a 26 varas *

993.580

48,72

61.225

3,00

229.593

11,26

25.230

1,24

192.420

9,42

5. Alcabalas ( $8 \%$ sobre valor en venta)

1.502 .048

73,66

TOTAL

2.039 .088

100,00

2.405 .260

d) Valor en venta de los paños (110 rs./vara)

366.172

e) Beneficio (d-c)

17,96

f) Porcentaje de e sobre $c$

* La arroba castellana pesa $11,5 \mathrm{Kgs}$.; la vara mide 0,836 metros.

FunNT:: Actas y Memorias de la Real Sociedad Económica de los Amigos del País de la Provincia de Segovia, vol. III, Segovia, 1793, pp. 33-37; datos reorganizados por el autor. 
Viene a cuento aquí referirnos a las estimaciones de algunos relevantes tratadistas de época respecto a la proporción existente entre el valor de las lanas exportadas y el valor de los paños extranjeros vendidos en España. Luis Ortiz escribió en 1558 en su célebre Memorial para que no salga dinero del reyno que:

... de una arroba de lana que a los extranjeros cuesta quince reales, azen obraje de tapicerías y otros paños y cosas labradas fuera de España, de que buelben dello mismo a ella, balor de más de quince ducados... ${ }^{43}$.

O sea, que según Ortiz el valor de los paños en venta es once veces mayor que el valor de la lana extraida con la que se ha confeccionado: 165 reales frente a 15 de la lana.

Más moderadas son las estimaciones de Gerónimo de Uztáriz hacia 1724:

... sacándonos con el valor de un millón de nuestro propio material, hasta quatro, ò mas millones en dinero, por cuyo medio nos debilitan, y hacen despoblar nuestras provincias, lo que en substancia viene a ser, dar armas, y municiones à nuestros emulos... ${ }^{44}$.

En este caso e interpretando que en los cuatro o más millones que «nos sacan» no incluye Uztáriz el valor de la lana, el valor de los paños sería cinco o más veces el valor de aquélla. Jovellanos menciona la estimación de Uztáriz y la da por buena en su Informe ... en el Expediente de la Ley Agraria ${ }^{45}$.

Lo que sobre el tema indica el Cuadro 3 que comentamos es que si se compara el valor de la lana lavada exclusivamente - sin incluir los derechos de exportación y el transporte hasta la fábrica extranjera- con el valor de los paños en venta, éste era 6,6 veces mayor que aquél; si se incluyen en el valor de la lana todos los gastos hasta llegar a la fábrica extranjera, entonces el valor del paño sería 4,79 veces el valor de la lana. De aquí se deduce que las estimaciones de Uztáriz, aceptadas por Jovellanos, eran razonables. Exageradas parecen las de Ortiz, pero habría que conocer mejor la situación de mediados del siglo XvI para asegurarlo.

El segundo testimonio de época lo proporciona Tomás Pérez Estala ${ }^{46}$ en

${ }^{43}$ Luis Ortiz (1558), p. 581.

44 Uztáriz (1742), p. 280.

45 Jovellanos (1795), p. 42

46 Pérez Estala, turolense de nacimiento, fue una de las más brillantes personalidades de la ciencia tecnológica de la Ilustración; pensionado por el erario regio, visitó varios países extranjeros para conocer su desarrollo tecnológico. Pero quizá lo que más interese subrayar aquí de su biografia es que contrajo matrimonio con una de las hijas de Laureano Ortiz de Paz, el innovador fabricante segoviano propietario del primer establecimiento privado - Ortiz de Paz compró 
un informe presentado en 1803 a una Junta Extraordinaria, de la que era miembro, mandada formar por la Secretaría de Hacienda para proponer iniciativas sobre tanteo de lana, fomento ganadero e industrial ${ }^{47}$.

Pérez Estala compara en su informe los costes de producción de paños superfinos en la fábrica que él dirigia en Segovia con los costes de confección, con lana española, de dichos géneros en las fábricas de Abbeville y Carcasona, en Francia. En los tres casos se trata de manufacturas con un alto grado de concentración del proceso productivo. La de Segovia era la Real Fábrica de los herederos de Ortiz de Paz, único establecimiento verdaderamente fabril existente en la ciudad por 1803; producia paños «comunes» —en el contexto industrial segoviano tal expresión quiere indicar géneros 22nos. (veintedosenos) sobre todo ${ }^{48}$-, pero también superfinos; el hilado se realizaba por lo general fuera del establecimiento mediante el recurso al sistema de encargos a las «fábricas de hilazas» dispersas por la provincia y también a campesinos-artesanos de los pueblos del entorno de la ciudad - Verlagssystem-; por lo que respecta al tejido, se ejecutaba en telares ubicados en la fábrica, aunque en el caso de los paños «comunes» se recurría a veces también a encargos a los tejedores de talleres domésticos dispersos por la ciudad; en consecuencia, la mayor parte del proceso productivo se realizaba en el interior del establecimiento por medio de operarios contratados, según los casos, a jornal o a destajo. En el caso de Abbeville se trataba de una fábrica con un mayor grado de concentración aún que la segoviana; estaba especializada en la producción de paños superfinos; cuando hacia 1750 la visita Antonio de Ulloa informa de que

las instalaciones de la Real Fabrica de Paños Superfinos creada en 1763- digno de la calificación de fabril que funcionó en Segovia. Es más, por expreso deseo testamentario del mismo Ortiz de Paz, Pérez Estala fue designado director del establecimiento tras la muerte de aquél en 1788. Hay que tener en cuenta, pues, que es desde su experiencia como director de un establecimiento verdaderamente fabril - a ello hace frecuentes alusiones en su escrito- como redacta su informe, desde luego autorizado, fehaciente y digno de crédito: los datos relativos a Segovia son los de la fábrica que dirigia. Sobre la fábrica de Ortiz de Paz puede verse García Sanz (1989).

47 Archivo General de Simancas, sec. Consejo Supremo de Hacienda Junta de Comercio y Moneda), leg. 363, exp. 34. Sobre el hallazgo de este importante documento puede verse la nota 26.

48 Esto es, paños con 22 cientos - 2.200- de hilos en urdimbre o pie. Cuanto mayor sea el número de hilos, más elevada es la calidad del género. De los 30nos. para arriba se consideran «superfinos». 


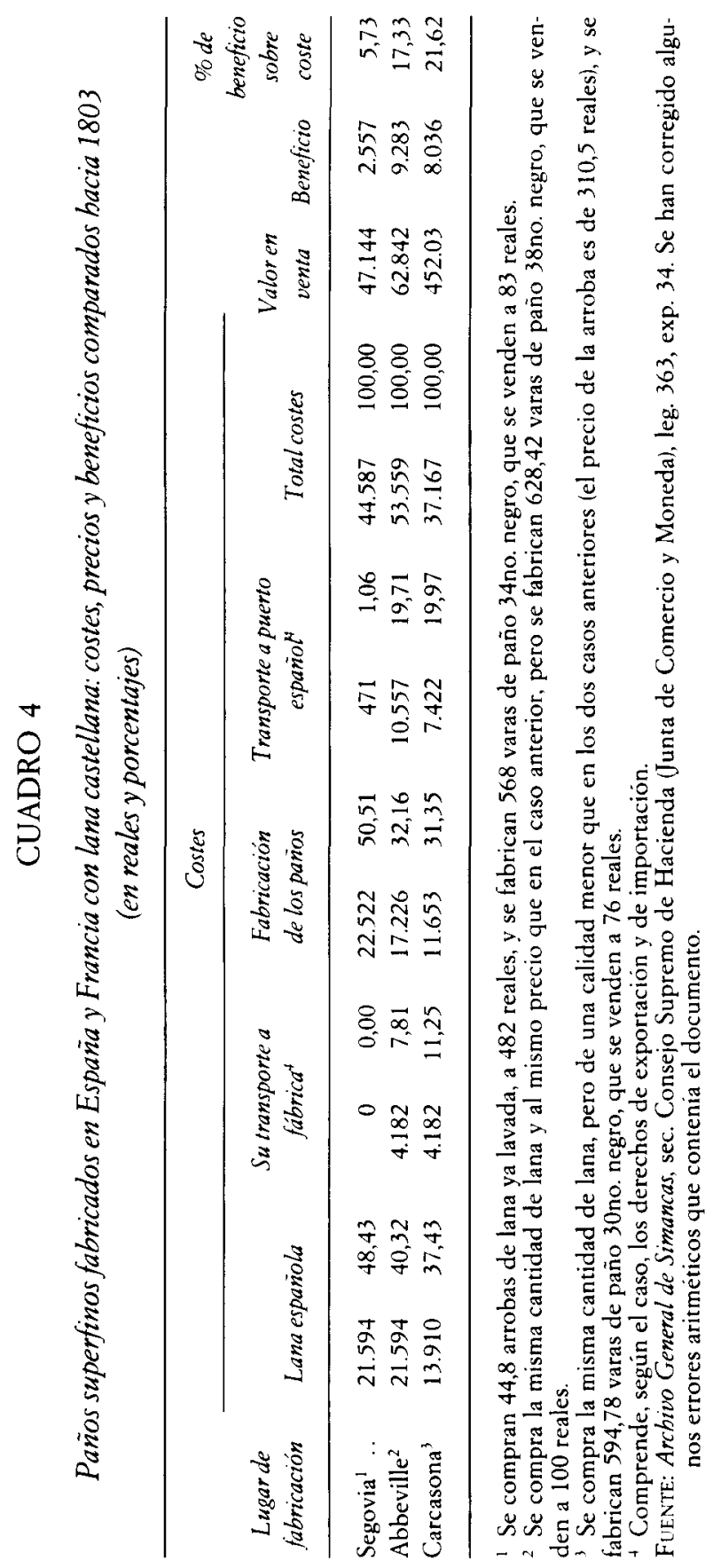




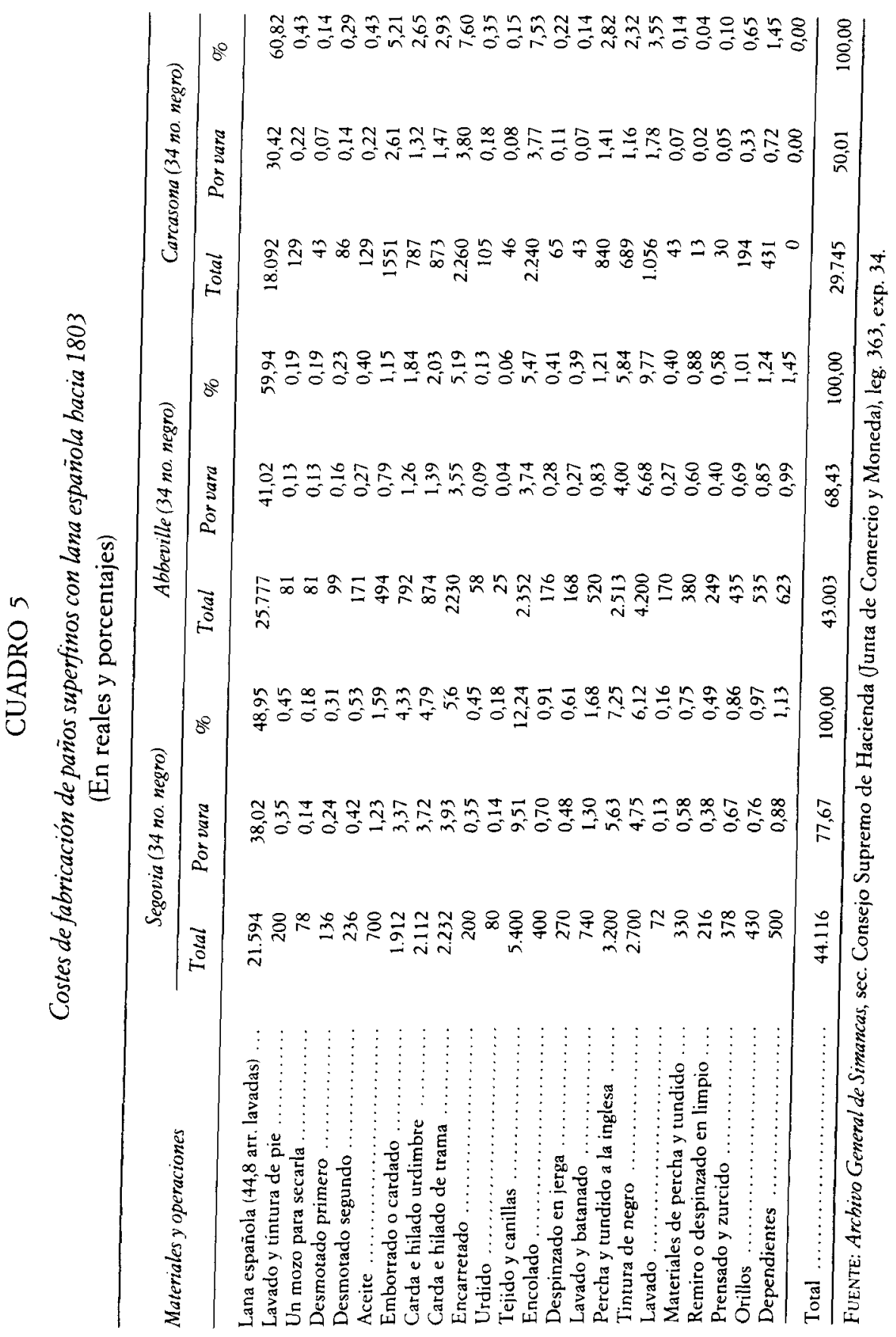


En Abbeville tuve no poco que admirar la manufactura de Paños y que dentro de la casa de un simple particular trabajen diariamente 3.500 personas, en 106 telares, y las demás oficinas correspondientes ${ }^{49}$.

Por su parte, el caso de Carcasona es más similar al de Segovia por el grado de concentración fabril; se trata también de una Manufactura Real en manos privadas; aunque algunas de las operaciones iniciales de la fabricación se realizan fuera del establecimiento por el sistema de encargos, la mayoría y las más importantes se ejecutan dentro, ya a mediados del siglo, según informa Antonio de Ulloa ${ }^{50}$. Tanto en Abbeville como en Carcasona en la segunda mitad del XviII se utilizaba ya la lanzadera volante ${ }^{51}$.

Pues bien, en el Cuadro 4 se sintetiza lo fundamental del informe de Pérez Estala. Los datos hablan por sí mismos: mientras en la fábrica de los Ortiz de $\mathrm{Paz}$, de Segovia, el coste de las maniobras de fabricación de los paños superfinos representaba algo más de la mitad de toda la inversión de capital circulante, en las fábricas de Abbeville y Carcasona dicho coste no alcanzaba a significar ni la tercera parte. Esta "economia en las maniobras" compensaba con creces el mayor gasto que debian hacer los fabricantes extranjeros por el transporte y pago de derechos aduaneros correspondientes a la exportación de la materia prima y a la importación de los paños. Pero, además, los fabricantes extranjeros eran capaces de confeccionar, con la misma clase de lana que empleaban los segovianos, paños de superior calidad que, naturalmente, lograban cotizaciones más elevadas - compárese en concreto el caso de Segovia y el de Abbeville, la primera fabricando paños 34 nos. y la segunda 38 nos.

El Cuadro 5 amplia nuestra lente de análisis y así podemos detectar en concreto cuáles eran las fases del proceso productivo en las que los fabricantes franceses lograban mayores ahorros relativos que los Ortiz de Paz. Eran especialmente cuatro las «maniobras» que encarecian relativamente los géneros españoles: el emborrado o "cardado en grande», la carda e hilado de la urdim. bre, la textura y, en fin, la percha y tundido. Estos cuatro renglones del gasto de fabricación suponian en la fábrica de Segovia un desembolso de 12.624 reales, mientras que en Abbeville era de 6.531 y en Carcasona de 4.589, esto es,

49 Archivo General de Simancas, sec. Secretaria de Marina, leg. 712, fol. 718 y ss. Debo esta noticia a Juan Helguera Quijada.

so Archivo General de Simancas, sec. Secretaria de Marina, leg. 712, fol. 631 y ss. Debo también esta noticia a Juan Helguera. Sobre la industria textil en el distrito de Carcasona pueden verse las obras de James K. J. Thomson (1982) y de Marquié (1993).

51 Una sintesis reciente sobre la situación de la industria textil francesa en la época que tratamos, con abundantes referencias a la pañeria de las ciudades aquí contempladas, puede verse en Butel (1993), pp. 201-239. 
respectivamente, un 48,27 y un 63,65 por 100 menos que en Segovia. Las cuatro operaciones señaladas eran las más intensivas en aplicación de trabajo 52 .

El Cuadro 6 sintetiza, con sus datos resolutivos - costes y precios de venta por vara-, lo que se viene exponiendo: la competitividad de los géneros extranjeros en el mercado nacional español a pesar de que fueran fabricados con lana comprada en España.

\section{CUADRO 6}

Costes y precios de venta en puerto español por vara de paño de color negro fabricado con lana castellana en 1803

(En reales)

\begin{tabular}{|c|c|c|c|c|}
\hline Clase de paño y localidad & $\begin{array}{c}(A) \\
\text { Costes }\end{array}$ & $\begin{array}{c}\text { (B) } \\
\text { Precio de } \\
\text { vente }\end{array}$ & $\begin{array}{c}\text { (C) } \\
\text { Beneficio }\end{array}$ & $\begin{array}{c}\text { (D) } \\
\text { Porcentaje } \\
\text { C sobre } A\end{array}$ \\
\hline 38no. Abbeville & 85,22 & 100 & 14,78 & 17,33 \\
\hline 30no. Carcasona & 62,48 & 76 & 13,52 & 21,62 \\
\hline 34no. Segovia $\ldots \ldots \ldots \ldots \ldots \ldots \ldots \ldots \ldots \ldots \ldots \ldots \ldots \ldots$ & 78,50 & 83 & 4,50 & 5,73 \\
\hline 24no. Segovia $\ldots \ldots \ldots \ldots \ldots \ldots \ldots \ldots \ldots \ldots \ldots \ldots \ldots \ldots \ldots$ & 56,68 & 60 & 3,32 & 5,85 \\
\hline 22no. Segovia ${ }^{1} \ldots \ldots \ldots \ldots \ldots \ldots \ldots \ldots \ldots \ldots \ldots \ldots \ldots \ldots \ldots$ & 47,10 & 48 & 0,90 & 1,91 \\
\hline
\end{tabular}

El informante, Tomás Pérez Estala, advierte respecto a este paño que para sus cálculos parte del supuesto de que tanto la lana de urdimbre como la de la trama son de la misma calidad -esto es, lana S (segunda) fina--, siendo así que, según él mismo indica, lo habitual en Segovia era que para la urdimbre se emplease lana menos fina, pero de fibra más larga, que para la trama; por tanto, eliminado este supuesto, el beneficio sería en este paño mayor que el indicado.

Fuente: Archivo General de Simancas, sec. Consejo Supremo de Hacienda (Junta de Comercio y Moneda), leg. 363, exp. 34.

52 Mann (1971), pp. 320-321, proporciona datos sobre la estructura de costes de fabricación de paños superfinos en una ciudad inglesa, Trowbridge, en 1798. Aunque, como advierte la misma autora, el caso no es del todo fiable habida cuenta de que los que declaran dichos datos son fabricantes que pretendian demostrar que sus beneficios eran bajos mientras no subieran los precios de los paños al ritmo que los de la lana, a pesar de ello se aprecia una notable similitud con la estructura de costes de las ciudades francesas consideradas: la materia prima -lana española- significaba un 56,24 de los costes y la vara de tejido salía por 68,88 reales. 


\section{COMPETITIVOS EN LANAS, PERO NO EN PAÑOS: LAS EXPLICACIONES}

Las cuestiones a tratar en este apartado son dos. La primera: por qué se exportaba parte de la lana utilizable en la pañeria y no se transformaba en su totalidad en el pais, comportamiento que tradicionalmente ha sido calificado por la historiografia como «irracional» y plasmación incuestionable del atraso económico español. La segunda: por qué los paños extranjeros fabricados con lana española podian competir, y de hecho competian, ventajosamente en el mercado español con los paños nacionales.

El planteamiento de este grave tema siempre me evoca la explicación que ofreció Jordi Nadal a por qué en el siglo xix la siderurgia española podía ser competitiva en productos semielaborados — cuyos inputs fundamentales eran el excelente mineral vasco y un escaso consumo de combustible: el carbón español es caro y de mala calidad - y no lo era en artículos acabados -precisados de mucho combustible para su elaboración, lo que elevaba sus costes hasta restarles toda competitividad en el exterior - ${ }^{53}$.

Creo que, mutatis mutandis, lo sustancial de esta argumentación de Nadal es aplicable a nuestro tema.

Empecemos por la primera cuestión: por qué éramos competitivos en la. nas y, en consecuencia, la lana española invadia los mercados exteriores.

La relación precio-calidad de nuestras lanas hacía que fueran baratas en comparación con las extranjeras. Los costes de producción de nuestra fibra eran relativamente bajos - por «relativamente» quiero significar, aqui y en lo sucesivo de este apartado, «en comparación con otros paises europeos»- por dos razones fundamentales. La primera es de carácter geográfico y, subsidiariamente, demografico: la existencia en nuestro país de extensas superficies incultas y aprovechables exclusivamente como pastos naturales, con una densidad demográfica verdaderamente baja, casi desérticas por la aridez climática que desaconseja el cultivo. Así se dispone de un factor tierra-para-pasto abundante y con un coste de oportunidad bajísimo - no ocurre lo mismo en otros paises europeos, salvo quizá en algunas zonas de los paises, como el nuestro, mediterráneos- La segunda razón de la relativa baratura de nuestras lanas es de carácter histórico-institucional: los privilegios del Honrado Concejo de La Mesta - supongo que algo similar ocurría con las instituciones ganaderas de la Corona de Aragón-, al hacer muy barato el tránsito por las cañadas y al mitigar el alza de los precios de arrendamiento de las hierbas invernales y, en cier-

\footnotetext{
53 Nadal Oller (1975), pp. 154-187.
} 
tos casos, también de las estivales, dado que de hecho reservaban el mercado de pastos para los ganaderos trashumantes, determinaban unos bajos costes relativos de la producción de lana esquilada a las cabañas trashumantes. Por estas dos razones puede comprenderse que la lana española, en general, y la fina merina esquilada a cabañas trashumantes, en particular, considerada la relación calidad-precio, pudiera competir con éxito en el mercado europeo: ninguno de los demás países europeos contaba con condiciones naturales, demográficas e histórico-institucionales tan propicias al efecto como España, circunstancias que en conjunto constituían el fundamento del monopolio español de lana de superior calidad ${ }^{54}$.

Jovellanos, que, como es bien sabido, fue uno de los personajes más críticos de la Mesta, a la que definía como «concejo de señores y monges convertidos en pastores y grangeros», sin duda tenia presentes las consideraciones que acabo de exponer cuando escribe:

Pero la Sociedad [Económica Matritense] no se dexará deslumbrar con tan especioso raciocinio [que los extranjeros se benefician de las lanas españolas]. ¿Pues qué, mientras no podamos [los españoles], no sepamos, o no queramos ser industriosos, será para nosotros un mal pagar por el valor de nuestras lanas una parte de la industria extrangera, cuyo consumo haya forzosa nuestra pobreza, nuestra ignorancia, o nuestra desidia? ... ¿Tanto nos ha de alucinar el deseo del bien, que tengamos el bien por mal? 55.

Pasemos a la segunda grave cuestión: por qué, si éramos competitivos en lanas, no lo éramos en las manufacturas fabricadas con dicha materia prima. Ello determinaba varios hechos de sobra conocidos y denunciados reiteradamente por los coetáneos de todas las épocas. En primer lugar, que los géneros nacionales eran incapaces de conquistar mercados en el exterior debiendo limitar su venta al protegido mercado interior $y$, como mucho, al cautivo mercado colonial. En segundo lugar, que los paños extranjeros, los importados legalmente $\mathrm{y}$ aún más los introducidos por contrabando, pudieran competir ventajosamente con los géneros nacionales, incluso en el caso nada infrecuente de que aquéllos hubieran sido fabricados con lana española.

Veamos qué motivos alegaban los coetáneos para explicar la falta de competitividad de los paños españoles frente a los extranjeros importados hechos con lana española $o$, si se prefiere, para explicar los bajos costes relativos de

${ }^{54}$ Creo muy valiosas las reflexiones que sobre los origenes y desarrollo de la trashumancia castellana y de su institucionalización expuso Bishko (1967, pero escrito en 1958) en un trabajo lleno de sugerencias en que se conjugan factores geográficos e históricos.

"Jovellanos (1795), p. 43. 
los géneros extranjeros frente a los españoles, según se ha evidenciado en los datos de los Cuadros 3, 4, 5 y 6 .

La Sociedad Económica segoviana, que estudió concienzudamente la cuestión a principios de los años noventa del XvIII, enumera hasta siete motivos de los altos costes relativos de los paños españoles, enumeración que, eliminando las implicaciones evidentes, se puede reducir a tres motivos, todos ellos encaminados a explicar «la economia en las maniobras» de que gozan los fabricantes extranjeros.

El primer motivo que aducen los ilustrados segovianos es el atraso tecnológico causado por la persistencia del mismo procedimiento de fabricación que consagraban las Ordenanzas del Obraje de los Paños publicadas en Sevilla jen 1511 ! Es más, en 1733 se había redactado una refundición de aquellas viejas ordenanzas en la que se renovaba y aun se acentuaba el reglamentismo en los procedimientos, elevando además las penas contra los contraventores. Así era impensable la innovación tecnológica necesaria para lograr la «economía en las maniobras». Un texto bien claro al respecto, debido a la pluma del ya mentado José Antonio de Horcasitas y redactado algunos años antes del informe que comentamos de la Segoviana, reza asi:

... pues zqué Maestro ha de dedicarse á adelantar en la [maniobra] que exercita, si no puede encontrar utilidad, ni dexar de ser multado quando se halle que executa la labor en menos tiempo que el señalado por los reglamentos? De modo que se le gradúa de delito la aplicación y la habilidad. ...Y si a los Artifices se les priva de libertad para discurrir ¿dónde está el camino de economizar? ${ }^{56}$.

Según la Económica, el anquilosamiento de las técnicas productivas era especialmente grave en lo tocante a la operación de la tintura y es muy interesante que la Sociedad proponga aplicar en Segovia a fines del siglo XviII las Ordenanzas de los Tintoreros de Paris establecidas por ¡Colbert más de un siglo antes!:

En Segovia, por exemplo, el arte de teñir azul se halla todavía como quando comenzó á venir de la América su principal ingrediente, esto es el añil. Se ignora aun el modo de combinarle con el pastel, como lo executan los extrangeros para dar ã las lanas el turqui brillante superior al nuestro después de mas de cien años que ha que en París se practica este método, como se ve por las ordenanzas de los Tintoreros de esta capital dispuestas por el célebre Colbert, no

56 ACTAS Y MEMORIAS..., op. cit., vol. I, Segovia, 1785, pp. 282-283. 
obstante la franqueza con que los mismos Franceses han publicado esta importante operación en sus libros de Química ${ }^{57}$.

¿Cuál era a este respecto la situación de la pañería de Abbeville y Carcasona? $Y_{a}$ he adelantado que la pañería de estas ciudades utilizaba ya en la segunda mitad del siglo XvIII la lanzadera volante de Kay, lo que permitía ahorrarse uno o más salarios en la operación del tejido o textura, mientras que, según señala el propio Pérez Estala, en la fábrica que dirigía el telar seguía siendo atendida por dos operarios retribuido cada uno de ellos con 7 reales por dia de trabajo. Es probable que también en la carda, la percha y el tundido los fabricantes franceses aplicaban un grado de mecanización mayor que su colega segoviano: esto explica los notables ahorros que en esas operaciones lograban aquéllos frente a éste, según ya hemos apreciado en el Cuadro 5.

Parece, pues, verosímil el primer motivo alegado por la Segoviana para explicar los altos costes relativos en que incurría la producción pañera de alta calidad segoviana -y en esto creo que española en general, incluidas las Reales Fábricas ${ }^{58}$ - De lo que no estoy tan seguro es de la veracidad del diagnóstico que de este mal ofrecen los ilustrados segovianos. ¿El atraso tecnológico se debía a la falta de libertad de los fabricantes por causa de las reglamentaciones gremiales o, más bien, a la falta de un intervencionismo estatal, digamos, científico, de tradición colbertiana, como parece era el caso de la industria pañera de las ciudades galas mencionadas? ¿Por qué, si no, los ilustrados segovianos consideran deseable que se implanten en la ciudad las ordenanzas de los tintoreros de París? ¿No se percataban acaso de que no era congruente el, por una parte, clamar contra los reglamentos gremiales, causa del atraso tecnológico según ellos, y a la vez proponer que se apliquen una reglamentación del tintado que, además, databa de la época de Colbert?

El segundo motivo de la falta de competitividad de los paños alegado por la Económica segoviana no contempla el caso de la fábrica de los Ortiz de $\mathrm{Paz}$, sino el de la «fábrica común» de Segovia -esto es, todos los demás fabricantes-, organizada según el Verlagssystem. Este segundo motivo lo expresan así los ilustrados segovianos:

57 ACTAS Y MEMORIAS..., op. cit., vol. IV, Segovia, 1793, p. 39.

58 Es una lástima que de las más de 700 páginas que dedica González Enciso (1980) al estudio de la Real Fábrica de Guadalajara, apenas 5 -de la 653 a la 658 - se refieran al importante tema de los costes de producción y que de ellas no resulte nada concluyente respecto a lo aquí tratado. 
La falta de fidelidad que se nota en los Operarios, la qual en el dia puede decirse que ha llegado á ser descaro, siendo pocos los que no roban la lana del Fabricante, porque no se les dá castigo alguno á causa de ser excesiva la pena de este delito en las actuales circunstancias ${ }^{59}$.

En efecto, el Verlagssystem, vigente en Segovia desde por lo menos principios del siglo XVI ${ }^{60}$, ofrecía muchas ocasiones y oportunidades para que los campesinos y los artesanos urbanos a quienes hacían «encargos» los fabricantes - hay que tenerlo bien presente: «fabricantes sin fábrica», «mercaderes hacedores de paños», Verleger, en fin- pudieran cometer fraudes con la materia prima y «simples» - aceite, colorantes... etc.- que éstos les proporcionaban. ¿Cómo vigilar a las familias campesinas de los pueblos próximos que cardan e hilan la lana que les ha encomendado el lejano fabricante? $¿ Y$ a los artesanos urbanos de los diferentes oficios textiles que laboran en los talleres que tienen en sus casas?

El resultado era que la calidad de los paños no se correspondía siempre con la calidad de la lana y simples proporcionados por el fabricante. Era, claro, una forma de encarecer los costes.

En la ya copiosa historiografía sobre la industria textil precapitalista en Europa se asume como lugar común que la difusión del Verlagssystem desde los siglos bajomedievales implicó la libertad en los procedimientos productivos y, en consecuencia, innovaciones técnicas, al no alcanzar la jurisdicción de los antiguos gremios urbanos al ámbito rural por el que se extendía el Verlagssystem. Esta virtualidad del Verlagssystem no corresponde en absoluto a la realidad en el caso, al menos de los territorios de la antigua Corona de Castilla. Por eso me parece incorrecto considerar que el concepto de Verlagssystem implique necesariamente libertad en los procedimientos y fomento de las innovaciones técnicas. Lo que en Castilla ocurrió de hecho -el notable ejemplo segoviano lo acredita incuestionablemente- es que el Verlagssystem siempre estuvo sometido desde el punto de vista técnico a las ordenanzas gremiales de las urbes, donde radicaban los Verleger y donde se ejecutaban las últimas operaciones del obraje de los paños ${ }^{61}$.

El tercer motivo de los altos costes relativos que señala la Económica de

s9 ACTAS Y MEMORIAS..., op. cit., vol. IV, Segovia, 1793, pp. 37-38.

${ }^{60}$ Sobre esto puede verse Carande (1965), Ruiz Martin (1965-1967), Garcia Sanz (1987 y 1991a).

6. Considero muy acertada la caracterización que hacen Aracil y Garcia Bonafé (1978), p. 117, de la versión segoviana de Verlagssystem, que consideran similar a la florentina. No creo, sin embargo, que el fracaso final de la industria pañera en ambas ciudades se daba a las mismas causas, a la vista del estudio de Malanima sobre Florencia (1982), pp. 41.88 sobre todo. 
Segovia, y que en esta ocasión Pérez Estala reitera y profundiza, es que los trabajadores textiles españoles cobran salarios superiores a los que perciben sus colegas europeos. Oigamos a la Sociedad:

Además de estos estorbos [a los que se acaba de referir] que se oponen á nuestros progresos, y de que carecen por lo general los Extranjeros, tienen éstos las ventajas de resarcir las expensas de la exportación de nuestras lanas y de la introducción de sus texidos con la economia y buen régimen de sus Fábricas; á que sin duda contribuye mucho la aplicación, y en algunos payses la frugalidad de los artistas y operarios ${ }^{62}$.

Más claro y razonado es el texto del informe de Pérez Estala en 1803:

Otro enemigo tenemos más fuerte: la baratura de la obra de mano en otros Paises. Esta desigualdad es tan influyente que ahogará por mucho tiempo nuestra industria en materias que nos sean comunes; pero, por dicha, en la lana podemos aventajarnos una vez que es producción de nuestro suelo y que tenemos posesiones ultramarinas adecuadas al consumo y a la preferencia de nuestras la. vores.

La economia del jornal extranjero, dimanada de la baratura de los comestibles y menesteres groseros, es un mal que no se podrá enmendar hasta que la agricultura mude de aspecto; no obstante podemos compensarle, en cierto modo, por la comodidad de las materias primeras y por el equilibrio en las gavelas Aduanales. Con este advitrio habrá de contrapesarse también otra especie de ahorro que envuelve en si el jornal extranjero: él gana al dia de cuatro a ocho reales, pero emplea tres y cuatro horas más que el Castellano, ofreciendo una quarta parte y aun un tercio más de fruto líquido ${ }^{63}$.

Resulta que, al final, nos topamos con jla agricultura! Una agricultura menos productiva que la de aquellos otros países de donde nos llegan paños hechos con lana española y que compiten con éxito con los paños nacionales en el mercado interior. $Y$ es que a los trabajadores textiles de España hay que pagarles más que a sus colegas foráneos porque, habida cuenta de que la baja productividad relativa de nuestra agricultura - que repercute en mayores costes de producción de los comestibles y, por tanto, en sus precios-, si no fuera así se hallaría comprometida la existencia y reproducción de la fuerza de trabajo industrial. Además, asegura Pérez Estala, jos trabajadores extranjeros, con menores salarios que los españoles, laboran algunas horas más por jorna-

62 ACTAS Y MEMORIAS DE LA REAL SOCIEDAD ECONOMICA..., op. cit., vol. IV, Segovia, 1793, pp. 38-39.

63 Texto tomado del expediente 34 del legajo 363 de la sección Consejo Supremo de Hacienda (Junta de Comercio y Moneda) del Archivo General de Simancas. 
da! 64. En definitiva, mientras la agricultura española no «mude de aspecto», no se puede pensar en lograr «economía en las maniobras» 65 .

Ni la Sociedad Segoviana ni Pérez Estala se refieren a un factor adicional del encarecimiento de los comestibles en España: la repercusión en precio de la sobrecarga fiscal. Desde finales del siglo xvI, el «Servicio de los Millones»y un verdadero enjambre de «sisas municipales» se cebaron sobre los artículos de primera necesidad - carne, vino, aceite, etc.-, especialmente en las urbes ${ }^{66}$. $\mathrm{O}$ sea, que los altos salarios no sólo se debían al hecho estructural de poseer una agricultura poco productiva - hecho este, en mi opinión, achacable sobre todo, aunque no exclusivamente, a las desventajas relativas impuestas por el medio natural-, sino también a factores claramente históricos, de la concreta historia política y social del país.

La explicación es sugestiva -incide sobre uno de los temas más trascendentales de la historia económica española- y la considero teóricamente convincente. Otra cosa es llegar a verificarla rigurosamente con cifras y sobre datos verdaderamente comparables. Abundan series de precios de los comestibles y no faltan series de salarios de los peones de la construcción, y oficios similares, para los diferentes paises europeos ${ }^{67}$. No son tan frecuentes series de salarios

64 A la vista de los mismos papeles-borrador que acompañan el informe de Pérez Estala, esta afirmación no parece verosimil, dado que en dichos documentos se indica que la jornada de trabajo de los operarios textiles de Segovia va de las ocho de la mañana a las nueve de la tarde. ¿Es que acaso sus colegas extranjeros no dormian?

65 Siempre me ha parecido sugestivo, sobre la extrañeza que en otros países europeos suscitaba el hecho de que los españoles se aplicaran a la producción de manufacturas y no a la agricultura, el texto que reproduce Herr (1973), pp. 123-124, y corresponde a una queja que la ciudad de Nîmes envió en 1790 a la Asamblea Nacional francesa:

«Desde que la Corte de España ha adoptado un sistema que parece tan contrario a sus verdaderos intereses como al carácter de su pueblo, desde que con una población escasa y casi sin agricultura, ambicionando apoderarse de todas las manufacturas y de proveer sola las mercancias para el consumo inmenso de sus colonias, ha esperado vencer todos los obstáculos por medio de la prohibición rigurosa de todos los productos de fabricación extranjera, la rama principal de la fábrica de medias de seda de Nimes ha desaparecido y con ella el bienestar de una población numerosa cuyos brazos ocupaba en las ciudades y en el campo...».

El subrayado es mio.

66 Muy esclarecedor es en esto el preciso estudio de Gutiérrez Alonso (1989). Resulta que en el Valladolid de mediados del Seiscientos la acumulación de impuestos sobre los comestibles determinaba que el peón albañil había de dedicar al menos el jornal de 20 días para pagar los impuestos incorporados a los precios de dichos articulos.

67 Asi, por ejemplo, basandome en datos que ofrece Weir (1991) he llegado a calcular que, entre 1781 y 1787 , un peón de la construcción de Londres podia comprar con su jornal diario hasta 6,7 kilogramos de pan, mientras que el de París podía adquirir sólo $5 \mathrm{kgs}$. y el de Madrid una cantidad incierta entre 3,7 y $5,5 \mathrm{kgs}$. - depende del decisivo dato del peso que atribuyamos ia la hogaza de pan!, extremo que Hamilton (1988), p. 270, confiesa no tener claro. 
de obreros textiles dedicados a una concreta maniobra fabril o series de pagos a destajeros por obra realizada. En todo caso, para llegar a alguna conclusión válida habría que tener certeza sobre si son idénticas las condiciones $y$, sobre todo, la duración de la jornada de trabajo y los dias realmente trabajados al año, así como conocer con exactitud cuántas veces realiza al dia el trabajador a destajo la operación en que está especializado. También habria que conocer las estructura del gasto y el precio de los productos adquiridos por los obreros. Dispongo de bastantes de estos datos para los operarios de la fábrica de los Ortiz de Paz de Segovia, pero me faltan para los de los establecimientos de Abbeville y Carcasona, por lo que la verificación de este extremo queda pendiente por ahora. En cualquier caso, no está de más que señale que, según Pérez Estala, los jornaleros textiles extranjeros ganan al día entre 4 y 8 reales, mientras que en el establecimiento de los Ortiz de Paz ganaban, según oficios, entre 5 y 10 reales.

La conclusión general de este apartado - con independencia de algunos extremos por ilustrar con datos concretos- es que mientras los españoles nos dedicásemos a producir lana aprovechando las ventajas relativas de nuestro medio natural, la competitividad de nuestra fibra en los mercados europeos era incuestionable. Otra cosa era que nos dedicásemos a transformar la lana para fabricar paños de calidad susceptibles de demanda exterior. En este caso, las ventajas relativas de los fabricantes extranjeros eran abrumadoras por varias razones: la tecnología, la organización del proceso productivo y la baratura de los salarios.

Por tanto, competitivos en lanas, pero no en paños.

\section{LA FORTALEZA DE LA INDUSTRIA TRADICIONAL... HASTA EL SIGLO XIX}

Este apartado trata de resolver la aparente contradicción entre lo sostenido en el apartado segundo y lo expuesto en los apartados cuatro y cinco, aparente contradicción que se podría concretar en la siguiente cuestión: ¿Cómo, si eran tan competitivos los paños extranjeros, subsistió durante los siglos modernos en España y hasta las primeras décadas del XIX una respetable industria lanera especializada no sólo en géneros ordinarios sino también en paños de calidad?

Para responder a esta cuestión hay que empezar precisando que en las calidades pañeras en que verdaderamente eran competitivos los fabricantes extranjeros eran, al menos en el siglo XVIII, los géneros más finos, los llamados su- 
perfinos, que son precisamente en los que estaban especializadas las fábricas cuyos datos de costes recogen los Cuadros presentados. Quedaba para la industria nacional una amplia gama de calidades - desde los 26nos.28nos., para abajo-- en las que el grado de competitividad extranjera se iba reduciendo progresivamente hasta llegar a anularse, si los desembolsos ocasionados por el transporte y por el pago de derechos aduaneros - de la lana exportada y de los paños introducidos- se incrementaban tanto como para absorber el valor añadido. Cuanto más refinado y, por tanto, más caro fuera el paño, más inapreciables en la composición de costes resultaban los gastos del transporte y de los aranceles.

Esto explica que una directriz permanente en la política económica de la España del xviII fuera el fomento de la fabricación de paños superfinos para asi frenar la introducción de paños extranjeros. En este contexto es en el que hay que contemplar la creación de las Reales Fábricas dedicadas a la pañería fina, así como los favores regios que recibió la fábrica de Laureano Ortiz de $\mathrm{Paz}$ y sus herederos. Otro tanto, pero desde la época de Colbert, se hacía en Francia y de ello también se beneficiaron las fábricas de Abbeville y Carcasona. Pero resulta evidente, por los datos presentados sobre costes comparados de la fábrica segoviana y de las francesas, que la iniciativa gubernamental espanola fue un fracaso, y esto es extensivo a las Reales Fábricas del ramo, subvencionadas permanentemente por el erario.

Pero lo que interesa subrayar aqui es que quedaba un amplio campo para la actividad de la industria pañera tradicional española, especializada en la producción de paños ordinarios y finos, pero no superfinos. La «f́brica común» de Segovia, por ejemplo, siguió concentrando casi toda su producción durante el siglo XviI en paños 22nos. finos, que habían sido el fundamento de la prosperidad de la ciudad en el siglo Xvi. Para fabricar estos famosos paños - más estimados en el Quinientos que en el Setecientos, ya que, según Uztáriz, los géneros «comunes» de Segovia «vienen a quedar oy en la clase de los medianos comparados con los de aquellas dos Naciones (Inglaterra y Francia), 68 - sólo se empleaban lanas verdaderamente finas para la trama, mientras que para la urdimbre se utilizaban lanas de «inferior calidad», dice Pérez Estala.

He aquí, por tanto, un primer bastión de la «fortaleza» de la industria pañera tradicional 69: la mayor parte de la lana utilizable para la pañeria quedaba

68 Uztáriz (1742), p. 341.

69 El empleo de la expresión «fortaleza» en este contexto está inspirado en el trabajo de Saavedra y Villares (1985) sobre la «fortaleza» de la sociedad tradicional en la Galicia del Antiguo Régimen. 
a disposición de la industria nacional ${ }^{70}$, que satisfacia con sus géneros - algunos sólo razonablemente finos, como los de la «fábrica común» de Segovia; otros sencillamente ordinarios- el grueso de la demanda interior. Ya hemos visto cómo, según estimaciones razonables, en la segunda mitad del xvIII la industria nacional venia a transformar entre el 70 y 75 por 100 de la lana producida útil para la pañería.

En segundo lugar - y un segundo baluarte-, fue el mismo atraso en la organización del proceso productivo de la industria pañera tradicional española lo que la hizo resistente.

En este sentido, permitaseme que reitere que los datos de los Cuadros 4, 5 y 6 se refieren a manufacturas con un alto grado de concentración del proceso productivo. Por ello, se veían forzadas a retribuir a la numerosa mano de obra asalariada que empleaban de acuerdo con el precio de mercado de dicho factor productivo. Es más, consta documentalmente que los Ortiz de Paz lograron reclutar para su establecimiento a los más hábiles trabajadores de la «fabrica común» de Segovia ofreciéndoles salarios más elevados que los que estaban dispuestos a pagar los demás fabricantes de la ciudad ${ }^{71}$.

Menores jornales e inferiores pagos por destajos estaban obligados a satisfacer los empresarios textiles de la «fábrica común» de Segovia - y esto es extensible a la generalidad de los fabricantes pañeros dispersos por las numerosisimas poblaciones con cierta especialización en la pañería, no así a las Reales Fábricas del ramo-. Si bien el Verlagssystem, que todos ellos utilizaban como marco de organización del proceso productivo, daba ocasión a los operarios para perpetrar fraudes - como hemos visto denuncia la Económica segoviana-, también deparaba la oportunidad de emplear fuerza de trabajo retribuyéndola con unos salarios reales inferiores a los costes de la existencia y reproducción de dicha fuerza de trabajo. Es evidente que la mayor parte de las necesidades de las familias campesinas de los pueblos próximos a Segovia, a las que los «fabricantes sin fábrica» de la ciudad proporcionaban lana para que la cardasen e hilasen, estaban cubiertas por los ingresos que lograban de la labranza y de la crianza. Por lo que respecta a los artesanos urbanos que en sus talleres domésticos agregaban valor añadido a los productos textiles semielaborados que le encomendaban los citados fabricantes, ni el trabajo de la esposa

70 Al hilo de estos razonamientos, me atrevo a sugerir que es probable que en el siglo XVII, cuando la demanda pañera europea tendió a concentrarse en géneros confeccionados con lanas de fibra larga, más dúctil pero menos fina que la merina, la proporción de lanas ordinarias y en. trefinas tendiera a crecer en el volumen total de lana espanola exportada.

${ }^{71}$ Archivo Histórico Nacional, sec. Consejos, leg. 902, exp. 5. 
del artesano ${ }^{72}$, ni el de sus hijos y ni el de los aprendices ${ }^{73}$ se retribuía de acuerdo con el valor de mercado de su fuerza de trabajo - ¿pero existía de verdad tal mercado para estos trabajadores marginales?-: la autoexplotación del colectivo familiar y de las personas a él incorporadas está en el fondo de la explicación de la persistencia secular del artesanado dependiente de los «encargos» de los fabricantes pañeros.

En tercer lugar - y una tercera trinchera de la «fortaleza» de la industria tradicional一, el Verlagssystem se caracterizaba por la casa inversión en capital fijo -instalaciones, utillaje, etc.-, lo que posibilitaba una gran versatilidad y flexibilidad del capital empleado. En efecto, ante un incremento de la demanda textil, los «fabricantes sin fábrica» respondían con el cómodo expediente de incrementar la inversión de capital circulante - reversible a corto plazo- haciendo más encargos a más trabajadores que laboraban en sus talleres domésticos; una coyuntura inversa inducia un comportamiento también inverso, sin que el capital quedara inmovilizado e improductivo en instalaciones e implementos sin uso. En el caso de la industria segoviana esta versatilidad del «capital industrial» - en realidad, en Segovia, y seguramente en los demás centros textiles de importancia, la «hacienda" de los pañeros consistía en bienes de muy diversa naturaleza: tierras, ganados, fincas urbanas, dinero prestado..., de manera que entrecomillo lo de «capital industrial»- fue probablemente más acentuada que en otras partes. Al concurrir en la ciudad la doble circunstancia de ser notable centro textil y principal mercado de lanas de calidad, la mayoría de los «mercaderes hacedores de paños» participaba de la doble condición de fabricante y exportador de lana: dedicaban sus afanes empresariales preferentes a uno u otro trato, según pintara la coyuntura comercial de lanas - en el exterior - y de paños - en el interior.

Que tal era la realidad lo confirman abundantes testimonios, entre los que voy a reproducir sólo dos, notables por su claridad y fecha. Así, a mediados del siglo XVII, cuando la pañería segoviana está sumida en una profunda recesión, los representantes de los cardadores y pelaires se quejan al Corregidor de la ciudad denunciando que

Oy, Señor, va el trato mui a pique porque el mercader que a de haçer çien paños no açe quarenta y de aqui vamos biendo y experimentando que ay maliçia que embarcan la flor de la lana y con el desecho labran, cossa que biene a

72 Incluso en la fábrica de los Ortiz de Paz el trabajo de las mujeres se retribuia a la mitad que el percibido por los varones, según reconoce el mismo Pérez Estala.

73 Consta documentalmente que, en Segovia al menos, con frecuencia el padre del aprendiz pagaba al maestro artesano por enseñar el oficio al hijo de aquél. Testimonios sobre esto pueden verse en Garcia Sanz (1991a). 
ser gran descrédito de dicha fábrica. Además desto, Señor, los mercaderes, después que an ganado máquina de açienda y se han hecho rricos y poderosos con el sudor de los pobres, se ban desligando poco a poco y dexando el trato oy uno y mañana otro por el ynterés tan grande que diçen allan en la embarcación [de lanas] ${ }^{74}$.

El segundo texto data de 1784 y corresponde a un informe redactado por el intendente de Segovia sobre si los fabricantes - beneficiados por el derecho de tanteo- podían ser a la vez exportadores de lanas:

De declararse esta incompatibilidad, sería perjudicialíssima a las Fábricas del Reino, porque extraiendo, como extrahen, las lanas muchos Fabricantes de los más acaudalados y logrando en este negocio mayor interés que en el de sus Fábricas, sin embargo de ser bien crecidas, abandonarían estas y se dedicarian enteramente a la extracción [de lanas] ${ }^{75}$.

Pero la «fortaleza» de la industria tradicional también tenía debilidades, unos limites históricos de resistencia: cuando a lo largo del siglo xIX la mecanización progresiva de la industria pañera - el caso más importante y modélico fue el de Sabadell y Tarrasa, estudiados por Josep María Benaul ${ }^{76}$ - redujo espectacularmente los costes a la vez que perfeccionaba y estandarizaba los géneros producidos, la industria tradicional, precapitalista, dispersa, organizada según el Verlagssystem, victoriosa de coyunturas adversas a lo largo de siglos, acabó por saltar por los aires.

En Segovia, ni siquiera se salvó del desastre la fábrica de los Ortiz de Paz, cuya tecnologia fue profundamente renovada en las primeras décadas del xIX. Pero este establecimiento no saltó exactamente por los aires, sino que fue pasto de las llamas en dos ocasiones: 1817 y 1827. En ambas ocasiones se abrieron diligencias para averiguar la causa del incendio, sin que las investigaciones lograran aclarar responsabilidades. Tengo pocas dudas de que los dos incen-

${ }^{74}$ Este texto procede de la Biblioteca Nacional, sec. Manuscritos, núm. 6.734. Debo su conocimiento a Felipe Ruiz Martin.

75 Archivo Municipal de Segovia, sig. 1.039.

76 Benaul (1991). 
dios fueron provocados por la acción ludista de los artesanos y fabricantes tradicionales 77 .

En Segovia, el centro productor de paños de calidad más importante en España durante los siglos modernos ${ }^{78}$, se hunde la industria tradicional en la primera mitad del Ochocientos, pero en su caida arrastra prometedoras iniciativas de una nueva y renovada industria. Por si ello fuera poco, y esto lo considero aún con mayor capacidad explicativa del final de la industria pañera segoviana, en los años treinta del XIX la casa del marqués de Lozoya - paradigma de «segovianismo» y que hasta entonces se habia surtido de géneros de la fábrica de los Ortiz de Paz-empieza a gastar tejidos catalanes que compra en las tiendas de la misma Segovia. Después de esto no habia nada que hacer.

\section{REFERENCIAS BIBLIOGRAFICAS}

Actas y Memorias de la Real Sociedad Económica de los Amigos del País de la Provincia de Segovia (1785-1799), Segovia, Imprenta Antonio Espinosa, 5 vols.

Aracil Marti, Rafael, y Marius Garcia Bonafé (1974): Industrialització al Pais Valenciá: Alcoi, Valencia, Eliseu Climent.

- (1978): «Industria doméstica e industrialización en España», Hacienda Pública Española, 55, pp. 113-129.

BASAS FERNANDEZ, Manuel (1963): El Consulado de Burgos en el siglo xVI, Madrid, CSIC.

Benaul i Berenguer, Josep Maria (1991): La industria textil llanera a Catalunya, 17501870. El proces d'industrialització al districte industrial de Sabadell-Terrassa, Tesis de Doctorado, Barcelona, Universidad Autónoma.

BILbaO, Luis Maria (1983): «Exportación y comercialización de lanas de Castilla durante el siglo xVII (1610-1670)», El pasado histórico de Castilla y León, Burgos, Junta de Castilla y León, vol. II, pp. 225-243.

- y FeRnándeZ DE PINEDO, Emiliano (1982): «Exportations de laines, trashumance et ocupation de l'espace en Castille aux XVI, XVII et XVIIIème siècles», Migrations, Population and Occupation of Land (before 1800), Budapest.

BisHKo, Charles Julian (1967): «El castellano, hombre de llanura. La explotación ganadera en el área fronteriza de la Mancha y Extremadura durante la Edad Mediam, en Homenaje a Jaime Vicens Vives, Barcelona, Universidad, vol. I, pp. $201-218$ (escrito en 1958).

- (1982): «Sesenta años después: La Mesta de Julius Klein a la luz de la investigación subsiguiente», en Historia, Instituciones, Documentos, 8, pp. 1-49.

Butel, Paul (1993): L'économie française au XVIIle siècle, París Sedes.

77 Se trata de un caso similar al que refieren Aracil y Garcia Bonafé (1974) para Alcoy en la misma época, pp. 129-147.

78 Desde hace años trabajo en la elaboración de una monografia sobre la historia de la pañe. ria segoviana entre los siglos $\mathrm{XV}$ y $\mathrm{XIX}$. 
Canga Argüelles, José (1834): Diccionario de Hacienda, tomo II, Madrid, Imprenta de Marcelino Calero y Portocarrero.

Carande, Ramón (1965): Carlos V y sus banqueros. I. La vida económica en Castilla (15161556), Madrid, Sociedad de Estudios y Publicaciones.

Carmona Badta, Joám (1990): El atraso industrial de Galicia. Auge y liquidación de las manufacturas textiles (1750-1900), Barcelona, Ariel.

CARRERAS Albert (1990): Industrialización española: estudios de bistoria cuantitativa, Madrid, Espasa Calpe.

Casado Alonso, Hilario (1990): «El comercio del pastel. Datos para la geografía de la industria pañera española en el siglo XVI», Revista de Historia Económica, 3, pp. 523.548.

Censo de FRUTOS y manufaCtuRAS de 1799 (1803), Madrid, Imprenta Real.

Córdoba de la Llave, Ricardo (1990): La industria medieval de Córdoba, Córdoba, Caja Provincial de Ahorros.

Fernandez Otal, José Antonio (1993): La Casa de Ganaderos de Zaragoza. Derecho y trasbumancia a fines del siglo XV, Zaragoza, Institución Fernando el Católico.

Fontana Lázaro, Josef (1967): «El 'Censo de Frutos y Manufacturas' de 1799: un aná lisis crítico", Moneda y Crédito, 101, pp. 54-68.

(1970): «Colapso y transformación del comercio exterior español entre 1792 y 1827. Un aspecto de la crisis económica del Antiguo Régimen en España», Moneda y Crédito, 115 , pp. 3-23.

Fortea PEREZ, José Ignacio (1980): Córdoba en el siglo XVl: las bases demográficas y económicas de una expansión urbana, Córdoba, Monte de Piedad y Caja de Ahorros.

Franch Banavent, Ricardo (1991): «Ganaderia, exportación de lana e industria pañera al final del Antiguo Régimen: el dictamen de Tomás Pérez en 1803», Cuadernos de Investigación Histórica, 14, pp. 107-133.

Garcia Colmenares, Pablo (1992): Evolución y crisis de la industrio textil castellana. Palencia (1750-1990). De la actividad artesanal a la industria textil, Madrid, Ed. Mediterrá-

Garcia Pérez, Juan (1992): «La crisis-quiebra de la fábrica de paños en dos localidades de la Alta Extremadura. Los casos de Hervás y Torrejoncillo (1750-1940)», investigación presentada al Seminario del equipo investigador sobre "la industria extremeña, desde el siglo XviI basta nuestros días", Badajoz.

Garcia Sanz, Angel (1978): «La agonía de la Mesta y el hundimiento de las exportaciones laneras: un capitulo de la crisis económica del Antiguo Régimen en España», Agricultura y Sociedad, 6, pp. 283-356.

(1985a): «Algo más sobre el final de la Mesta y la crisis de la trashumancia: a propósito de la publicación de un "Tratado Práctico de Ganadería Merina" escrito en 1826», Agricultura y Sociedad, 34, pp. 275-338.

(1985b): "Crisis de la agricultura tradicional y revolución liberal (1800-1850)», en Angel Garcia Sanz y Ramón Garrabou, eds., Historia agraria de la España contemporánea. I. Cambio social y nuevas formas de propiedad (1800-1850), Barcelona, Crítica. (1986): Desarrollo y crisis del Antiguo Régimen en Castilla la Vieja. Economía y sociedad en tierras de Segovia de 1500 a 1814, Madrid, Akal (2.. ed.).

(1987): «Mercaderes hacedores de paños en Segovia en la época de Carlos V: organización del proceso productivo y estructura del capital industrial», Hacienda Pública Española, 108-109, pp. 65-79. 
- (1989): «Industria textil tradicional y las reformas de la Ilustración: las transformaciones de la pañería segoviana durante el reinado de Carlos III», Actas del Congreso Internacional sobre «Carlos III y la Ilustración», Madrid, Ministerio de Cultura, vol. II, pp. 363-387.

(1991a): «Organización productiva y relaciones contractuales en la pañería segoviana en el siglo XVI», en La manufactura urbana $i$ els menestrals (segles XIII-XVI), Palma de Mallorca, Govern Balear, pp. 177-192.

- (1991b): «Segovia y la industria pañera, siglos Xvi-XIX», Actas del Congreso de Historia de la Ciudad. Segovia, 1088-1988, Segovia, Academia de Historia y Arte de San Quirce, pp. 381-408.

- (1991c): «Población e industria textil en una ciudad de Castilla: Segovia, 1530 1750», en Jordi Nadal, coord., La evolución demográfica bajo los Austrias, Alicante, Instituto de Cultura Juan Gil-Albert, pp. 153-168.

GonZÁlez EnCISO, Agustin (1980): Estado e industria en el siglo XVIII: la Fábrica de Guadalajara, Madrid, Fundación Universitaria Española.

GRUPO DE ESTUDIOS DE HISTORIA RURAL (1991): Estadísticas bistóricas de la producción agraria española, 1859-1935, Madrid, MAPA.

Gutiérrez Alonso, Adriano (1989): Estudio sobre la decadencia de Castilla. La ciudad de Valladolid en el siglo Xvil, Valladolid, Universidad.

Hamilton, E. J. (1988): Guerra y precios en España, 1650-1800, Madrid, Alianza (1.a ed., 1947).

HERR, Richard (1973): España y la revolución del siglo xvII, Madrid, Aguilar.

Iradiel Murugarren, Paulino (1974): Evolución de la industria textil castellana en los siglos XIII-XVI. Factores de desarrollo, organización y costes de la producción manufacturera en Cuenca, Salamanca, Universidad.

ISRAEL, J. I. (1980): «Spanish Wool Export and the European Economy, 1610-1640», Economic History Review, XXXIII, pp. 193-211.

Jovellanos, Gaspar Melchor de (1795): Informe... en el Expediente de Ley Agraria, Madrid, Imprenta de Sancha.

KLein, Julius (1981): La Mesta. Estudio de la bistoria económica española, 1273-1836, Madrid, Alianza (1." ed., 1920, Cambridge, Harvard University Press).

Lapeyre, Henri (1974): «Les exportations de laine de Castille sous le regne de Philippe IIm, en La lana come materia prima. I fenomeni della sua produzione e circulazione nei secoli XIII-XVIII, Firenze, Istituto Internazionale di Storia Economica «Francesco Datini», pp. 221-239.

- (1981): El comercio exterior de Castilla a través de las aduanas de Felipe II, Valladolid, Universidad, pp. 165-209.

Larruga, Eugenio (1791): Memorias políticas y económicas, Madrid.

LE FLEM, Jean-Paul (1976): «Vraies et fausses sprendeurs de l'industrie textile sègovienne (vers 1460- vers 1650)», en Produzione, commercio e consumo dei panni di lana (nei secoli XII-XVIII), Firenze, Istituto Internazionale di Storia Economica «Francesco Datini», pp. 525-536.

LECEA GARCIA, Carlos (1897): Recuerdos de la antigua industria segoviana, Segovia.

Lozoya, Marqués de -Juan de Contreras y López de Ayala- (1921): Historia de las corporaciones de menestrales en Segovia, Segovia.

Llopis AGELAN, Enrique (1980): «Crisis y recuperación de las explotaciones trashumantes: la cabaña del Monasterio de Guadalupe (1597-1679)», Investigaciones Económicas, 13, pp. 125-168. 
(1982): «Las explotaciones trashumantes en el siglo xVIII y primer tercio del XIX: la cabaña del Monasterio de Guadalupe, 1700-1835», en Gonzalo ANES, ed.: La economía española al final del Antiguo Régimen. I. Agricultura, Madrid, Alianza-Banco de España, pp. 1-101.

(1993): «La formación del "desierto manufacturero" extremeño: el declive de la pañería tradicional al final del Antiguo Régimen», Revista de Historia Industrial, 3 (1993), pp. 41-63.

MANN, Julia de L. (1971): The Cloth Industry in the West of England from 1640 to 1880, Oxford, Clarendon Press.

MARQuí, Claude (1993): L'industrie textile carcassonnaise au XVIIIe siècle, Carcassonne.

Martin Garcta, Gonzalo (1989): La Industria Textil en Avila durante la etapa final del Antiguo Régimen. La Real Fábrica de Algodón, Avila, Diputación Provincial; por lo que respecta a la industria lanera, pp. 67-204.

Muret PONS, Assumpta (1989): «Protoindustria e industria dispersa en la Cataluña del siglo xvill. La pañeria de Esparraguera y Olesa de Montserrat», Revista de Historia ria Económica, vol. 7, núm. 1, pp. 45-67.

NADAL. OlLER, Jordi (1975): El fracaso de la revolución industrial en España, 1814-1913, Barcelona, Ariel.

Ojeda SAN Miguel, Ramón (1984): «Crecimiento y subsistencia de un centro rural burgalés (siglos XVI-XIX)», en El pasado bistórico de Castilla y León, vol. II, pp. 474-492, Salamanca, Junta de Castilla y León.

ORTIZ, Luis (1558): Memorial para que no salga dinero del reyno, Burgos; transcripción y edición de Manuel Fernández Alvarez: Economía, Sociedad y Corona, Cultura Hispánica, Madrid, 1963.

PAREJO Barranco, Antonio (1987): Industria dispersa e industrialización en Andalucía, Málaga, Universidad y Ayuntamiento.

(1989): La industria lanera española en la segunda mitad del siglo XIX, Málaga, Universidad.

Phillips, William D. (Jr), y Rahn Phillips, Carla (1977): «Spanish Wool and Dutch Rebels: The Middelburg Incident of 1574m, American Historical Review, 82, pp. 312-330.

PRADOS DE LA Escosura, Leandro (1988): De imperio a nación. Crecimiento y atraso económico en España (1780-1930), Madrid, Alianza.

Rahn Phillips, Carla (1982): «The Spanish Wool Trade, 1500-1780», Journal of Economic History, XLII, pp. 775-795.

(1983): «Spanish Merchants and the Wool Trade in the Sixteenth Century», The Sixteentb Century Journal, 3, pp. 259-282.

Ros Massana, Rosa (1993): La industria lanera de Béjar a mediados del siglo XVIII, Salamanca, Centro de Estudios Salmantinos.

Ruiz MARTIN, Felipe (1965-1967): «Un testimonio literario sobre las manufacturas de paños en Segovia por 1625m, en Homenaje al profesor Alarcos García, Valladolid, vol. II, pp. 787-807.

SaAvedra, Pegerto, y Villares, Ramón (1985): «Galicia en el Antiguo Régimen: la fortaleza de una sociedad tradicional», publicado en Roberto FERNANDEZ, ed.: España en el siglo xvil. Homenaje a Pierre Vilar, Barcelona, Crítica, pp. 434-504.

Tromson, James K. J. (1982): Clermont-de-Lodève, 1633-1789, Cambridge University Press. 
Torras Elías, Jaume (1984): «Especialización agrícola e industria rural en Cataluña en el siglo XviII", Revista de Historia Económica, vol. 2, núm. 3, pp. 113-127.

Uztariz, Gerónimo de (1742): Theoria y Practica de Comercio, y Marina, Imp. Antonio Sanz, Madrid, (1.a ed., 1724); hay edición de Madrid, 1968, editorial Aguilar.

WeIR, D. R. (1991): «Les crises économiques et les origines de la Révolution Française», Annales E.S.C., pp. 917-947. 